\title{
Entomotoxic Activity of the Extracts from the Fungus, Alternaria tenuissima and Its Major Metabolite, Tenuazonic Acid
}

\author{
Dilara Salimova ${ }^{1}$, Anna Dalinova ${ }^{1} \mathbb{D}$, Vsevolod Dubovik $^{1}{ }^{\mathbb{D}}$, Igor Senderskiy ${ }^{1}$, Elena Stepanycheva ${ }^{1}$, \\ Oksana Tomilova ${ }^{2}$, Qiongbo $\mathrm{Hu}^{3}$ (D) and Alexander Berestetskiy ${ }^{1, *(D)}$
}

1 Department of Phytotoxicology and Biotechnology, All-Russian Institute of Plant Protection, Podbelskogo Shosse, 3, Pushkin, 196608 Saint-Petersburg, Russia; d.salimova@vizr.spb.ru (D.S.); adalinova@vizr.spb.ru (A.D.); vdubovik@vizr.spb.ru (V.D.); senderskiy@mail.ru (I.S.); estepanycheva@yandex.ru (E.S.)

2 Institute of Systematics and Ecology of Animals SB RAS, Frunze Str. 11, 630091 Novosibirsk, Russia; toksina@mail.ru

3 Key Laboratory of Bio-Pesticide Innovation and Application of Guangdong Province, College of Plant Protection, South China Agricultural University, Guangzhou 510642, China; hqbscau@scau.edu.cn

* Correspondence: aberestetskiy@vizr.spb.ru; Tel.: +7-(812)-476-6838

Citation: Salimova, D.; Dalinova, A.; Dubovik, V.; Senderskiy, I.; Stepanycheva, E.; Tomilova, O.; Hu, Q.; Berestetskiy, A. Entomotoxic Activity of the Extracts from the Fungus, Alternaria tenuissima and Its Major Metabolite, Tenuazonic Acid. J. Fungi 2021, 7, 774. https:// doi.org/10.3390/jof7090774

Academic Editors:

Sengottayan Senthil-Nathan and Jae Su Kim

Received: 16 August 2021

Accepted: 13 September 2021

Published: 18 September 2021

Publisher's Note: MDPI stays neutral with regard to jurisdictional claims in published maps and institutional affiliations.

Copyright: (C) 2021 by the authors Licensee MDPI, Basel, Switzerland. This article is an open access article distributed under the terms and conditions of the Creative Commons Attribution (CC BY) license (https:// creativecommons.org/licenses/by/ $4.0 /)$.
Abstract: The study of fungal antibiotics in their competitive interactions with arthropods may lead to the development of novel biorational insecticides. Extracts of Alternaria tenuissima MFP253011 obtained using various methods showed a wide range of biological activities, including entomotoxic properties. Analysis of their composition and bioactivity allowed us to reveal several known mycotoxins and unidentified compounds that may be involved in the entomotoxic activity of the extracts. Among them, tenuazonic acid (TeA), which was the major component of the A. tenuissima extracts, was found the most likely to have larvicidal activity against Galleria mellonella. In the intrahaemocoel injection bioassay, TeA was toxic to G. mellonella and of Zophobas morio with an $\mathrm{LT}_{50}$ of 6 and 2 days, respectively, at the level of $50 \mu \mathrm{g} /$ larva. Administered orally, TeA inhibited the growth of G. mellonella larvae and caused mortality of Acheta domesticus adults ( $\mathrm{LT}_{50} 7$ days) at a concentration of $250 \mu \mathrm{g} / \mathrm{g}$ of feed. TeA showed weak contact intestinal activity against the two phytophages, Tetranychus urticae and Schizaphis graminum, causing $15 \%$ and $27 \%$ mortality at a concentration of $1 \mathrm{mg} / \mathrm{mL}$, respectively. TeA was cytotoxic to the Sf9 cell line ( $\mathrm{IC}_{50} 25 \mu \mathrm{g} / \mathrm{mL}$ ). Thus, model insects such as G. mellonella could be used for further toxicological characterization of TeA.

Keywords: Alternaria tenuissima; extract; bioassays; PCA; tenuazonic acid; Galleria mellonella; Zophobas morio; Acheta domesticus; Tetranychus urticae; Schizaphis graminum; Sf9

\section{Introduction}

Herbivores and phytopathogens inhabit the same ecological niches and use plants as a food source and, therefore, can compete for substrates. In this regard, some phytopathogenic microorganisms are assumed to produce metabolites that directly (because of entomotoxic or repellent action) or indirectly (through induced plant responses, suppressed immunity, and the symbiotic microbiota of insects) affect the fitness of arthropods. The study of the antagonistic effect of phytopathogenic microorganisms on the viability, development, and fertility of arthropods is important for the development of methods to control phytophagous insects and vectors of human and animal diseases [1].

Among phytopathogenic fungi, Alternaria species have the potential for the production of entomotoxic secondary metabolites. For instance, extracts of approximately $20 \%$ of tested isolates of nine Alternaria species showed aphicidal activity against the vetch aphid (Megoura viciae). The aphid was most sensitive to organic extracts from cultures of A. saponariae, A. japonica, A. penicillata, A. papavericola, and A. tenuissima [2]. An ethanolic extract from the mycelium of $A$. papavericola (Brachycladium papaveris) caused mortality of 
M. viciae comparable to the botanical insecticide NeemAzal [3]. Extracts from A. alternata cultures inhibited acetylcholinesterase and exhibited insecticidal and immunosuppressive activity against the cotton leafworm (Spodoptera litura) [4,5]. Extracts from A. destruens cultures that inhibited the activity of $\alpha$-glucosidase were toxic to $S$. litura with an $\mathrm{LD}_{50}$ of approximately $2 \mathrm{mg} / \mathrm{g}$ feed [6].

A number of entomotoxic compounds had been purified from cultures of several $\mathrm{Al}$ ternaria species. A. brassicae was found to produce depsipeptide phytotoxins, some of which (for example, destruxin B) demonstrate insecticidal properties [7,8]. Methyl-3,8-dihydroxy6-methyl-4-chloro-9-oxo-9H-xanthene-1-carboxylate and chloromonilinic acid B isolated from $A$. sonchi strongly affected (75\% mortality) the common wheat aphid (Schizaphis graminum) at a concentration of $1 \mathrm{mg} / \mathrm{mL}$ [9]. Altenuene produced by A. alternata led to $70 \%$ mortality of $S$. litura larvae at $5 \mathrm{mg} / \mathrm{g}$ feed [10]. Tenuazonic acid produced by some Alternaria species was toxic for the first instar larvae of the common green bottle fly (Lucilia sericata) $\left(\mathrm{LD}_{50} 120 \mu \mathrm{g} / \mathrm{mL}\right.$ ) [11].

Small-spored Alternaria spp. may be of special interest as possible producers of entomotoxic metabolites. These species have often been isolated from cadavers or hibernating stages of arthropods. They also demonstrate entomopathogenic properties [12-14]. In particular, the strains of the fungus preliminarily identified as A. infectoria infected eggs, larvae, and adults of the fig wax scale (Ceroplastes rusci) [15]. Interestingly, A. alternata strains that were pathogenic to various aphid species did not infect insects from other orders, suggesting the production of aphid-specific toxins by the fungus [16,17]. At the same time, small-spored Alternaria spp. of the section Alternaria (A. alternata, A. arborescens, A. gaisen, and $A$. tenuissima), which are widespread on various plant substrates as saprotrophs and are weak pathogens [18], can indirectly affect various arthropods through the production of phytotoxins or/and plant immunomodulators [19,20]. Therefore, although the small-spored Alternaria spp. are capable of infecting arthropods, the entomotoxic properties of their secondary metabolites are still poorly understood.

The earlier characterized strain MFP253011 of A. tenuissima [21] was chosen as the object of this study. The aim of this work was to reveal and characterize the determinants of A. tenuissima MFP253011 entomotoxicity. For this purpose, (1) the fungal cultures were grown on five liquid and solid substrates to extract the metabolites with two solvents and then to evaluate the spectrum of their bioactivity; (2) the composition of the extracts was analyzed in relation to the bioactivity to reveal entomotoxicity determinants and their possible indirect effects; and (3) tenuazonic acid (TeA), which was found to be a main component of extracts showing anti-insectan properties, was assayed against various species of model (Galleria mellonella) and feed (Zophobas morio and Acheta domesticus) insects as well as phytophages (Schizaphis graminum and Tetranychus urticae).

\section{Materials and Methods}

\subsection{Fungal Strain and Fermentation}

The strain MFP253011, gifted by Dr. Philipp Gannibal (Laboratory of Mycology and Phytopathology at the All-Russian Institute of Plant Protection, Saint Petersburg, Russia) and identified as A. tenuissima (Kunze) Wiltshire [21], was used in this study. The fungal culture was preserved on standard potato-dextrose agar (PDA) at a temperature of $5{ }^{\circ} \mathrm{C}$. To obtain extracts, the fungus was grown in $1 \mathrm{~L}$ Erlenmeyer flasks with $300 \mathrm{~mL}$ of a liquid medium. Four standard liquid synthetic and semisynthetic nutrient media that varied by carbon and nitrogen sources were used: modified Czapek media (MCM), M1D, YMG, and Sabouraud media (SAB). The composition (g per $\mathrm{L}$ of deionized water, $\mathrm{pH}$ ) was as follows: $\mathrm{MCM}$ (glucose-20, $\mathrm{NaNO}_{3}-2, \mathrm{KH}_{2} \mathrm{PO}_{4}-1, \mathrm{MgSO}_{4}-0.5, \mathrm{KCl}-0.5$, thiamine $1 \times 10^{-4}$, biotin-5 $\times 10^{-6}$ ), M1D (sucrose-45, ammonium tartrate-7.5, $\mathrm{MgSO}_{4} \times 7 \mathrm{H}_{2} \mathrm{O}$ $-5.25, \mathrm{Ca}\left(\mathrm{NO}_{3}\right)_{2}-0.45, \mathrm{KNO}_{3}-0.15, \mathrm{KCl}-0.15, \mathrm{NaH}_{2} \mathrm{PO}_{4}-0.03, \mathrm{FeCl}_{3} \times 6 \mathrm{H}_{2} \mathrm{O}-0.003$, $\mathrm{ZnSO}_{4} \times 7 \mathrm{H}_{2} \mathrm{O}-0.0375, \mathrm{H}_{3} \mathrm{BO}_{3}-0.003, \mathrm{KI}-0.015, \mathrm{MnSO}_{4}-0.75$ ), $\mathrm{YMG}$ (glucose-20, malt extract-10, yeast extract -4 ), and $\mathrm{SAB}$ (glucose -40 , peptone-10). 
The fungal culture was also grown on a solid substrate: $100 \mathrm{~g}$ of pearl barley (PB), $60 \mathrm{~mL}$ of water in $500 \mathrm{~mL}$ Erlenmeyer flasks. All the media used in this study were sterilized by autoclaving at $121^{\circ} \mathrm{C}$ for $20 \mathrm{~min}$. Agar blocks ( $5 \mathrm{~mm}$ in diameter) cut from the edge of one-week $A$. tenuissima colonies obtained on PDA at $24{ }^{\circ} \mathrm{C}$ were used as seed inoculum (two blocks per flask). Incubation of the fungus was carried out at a constant temperature of $24{ }^{\circ} \mathrm{C}$ in the dark without agitation for three weeks for the liquid cultures, while the solid cultures were grown for two weeks and shaken once a day to improve aeration and prevent clumping. Three biological replicates were used for each culture medium.

\subsection{Extraction of Secondary Metabolites}

The mycelium was separated from the culture liquid by filtration through cheesecloth. Culture filtrates of $A$. tenuissima (300 mL each) were adjusted to $\mathrm{pH} 7$ with $0.1 \mathrm{~N} \mathrm{NaOH}$ and extracted with dichloromethane $(\mathrm{DCM})(2 \times 150 \mathrm{~mL})$. Then remaining aqueous phases were adjusted to $\mathrm{pH} 3$ with formic acid and repeatedly extracted with ethyl acetate (EtOAc) $(2 \times 150 \mathrm{~mL})$. The dry solid culture was blended and extracted repeatedly with $300 \mathrm{~mL}$ of a mixture of acetone and water $(50: 50, v / v)$. After evaporation of the organic solvent, water phase was successively extracted with hexane and EtOAc twice for each solvent. The extracts were dried over anhydrous sodium sulfate and evaporated to dryness under vacuum at $40{ }^{\circ} \mathrm{C}$.

\subsection{Analysis of Extracts}

Acetonitrile was used to dissolve the extracts samples to a concentration of $5 \mathrm{mg} / \mathrm{mL}$. They were analyzed with an Acella high-performance liquid chromatography (HPLC) system with a diode-array detector and TSQ Quantum Access ${ }^{\mathrm{TM}}$ triple quadrupole mass spectrometer (Thermo Scientific, Waltham, MA, USA). The analysis was performed on a Zorbax SB-C18 column (Agilent Tech., Santa Clara, CA, USA, particle size $1.8 \mu \mathrm{m}, 4.6 \times 150 \mathrm{~mm}$ ) with an eluent flow of $250 \mu \mathrm{L} / \mathrm{min}$ and a column temperature of $40{ }^{\circ} \mathrm{C}$ in a solvent system of acetonitrile- $0.1 \%$-formic acid in the gradient mode; acetonitrile concentration increased from 1 to $95 \%$ during the first $17 \mathrm{~min}$, remained at $95 \%$ of acetonitrile for $3 \mathrm{~min}$. The volume of the injected samples was $2 \mu \mathrm{L}$. The samples were analyzed in the positive mode in the scanning range of 100-1000 m/z using heated electrospray ionization. The retention time $\left(t_{R}\right), m / z$ values, and UV spectra of the metabolites were analyzed to compare the chromatographic profiles of the extracts.

The relationship between the composition of extracts ( 9 major compounds) obtained by different methods (5 media $\times 2$ extraction solvents) and their biological activity (9 organisms) was assessed using principal component analysis (PCA) with data standardization prior to the analysis. Additional data on toxicity extracts to radish and Paramecium caudatum were taken from a published study [21].

\subsection{Isolation of Tenuazonic Acid}

The submerged fermentation of $A$. tenuissima MFP253011 was conducted in a $7 \mathrm{~L}$ bioreactor (Applikon Biotechnology, Delft, the Netherlands) containing 4.75 L of YMG medium for 7 days. A $250 \mathrm{~mL}$ volume of starter culture was grown in a $750 \mathrm{~mL}$ Erlenmeyer flask with the same medium that was inoculated with two agar blocks of the fungus colony on PDA (5 mm in diam) and incubated on a rotary shaker (at $180 \mathrm{rpm}$ ) at a temperature of $24{ }^{\circ} \mathrm{C}$ for 7 days. The conditions of submerged fermentation were as follows: incubation temperature $24{ }^{\circ} \mathrm{C}$, aeration level $1 \mathrm{vvm}$, rotation speed $400 \mathrm{rpm}$, and initial pH 5.9 (not maintained at a constant level). Sunflower oil $(1 \%, v / v)$ was added to the medium as an antifoam before the inoculation.

Extraction of metabolites from culture filtrate was performed as described in Section 2.2. The crude EtOAc extract (1272 mg) was separated on a glass column packed with Bio-Beads SX-8 resin (Bio-Rad, Hercules, CA, USA) using a mixture of DCM-EtOAc -formic acid (49.9:49.9:0.2, $v / v$ ) as the eluent with a flow rate of $5 \mathrm{~mL} / \mathrm{min}$. The resulting TeA-containing fraction II $(890 \mathrm{mg})$ was applied to a Chromabond C18ec cartridge (10 g, 
Macherey-Nagel, Düren, Germany), and the column was eluted sequentially with $40 \mathrm{~mL}$ of $\mathrm{MeOH}-0.1 \%$ formic acid mixture $(25: 75,50: 50,75: 25,100: 0, v / v)$, yielding five subfractions (A-E). Subfraction B $(775 \mathrm{mg})$ was further purified by preparative HPLC to afford TeA (475 mg) as yellow oil (XBridge Prep C18 $5 \mu \mathrm{m}$, column size $19 \times 250 \mathrm{~mm}$, elution with $30 \%$ acetonitrile in $0.1 \%$ formic acid, flow rate $24 \mathrm{~mL} / \mathrm{min}$, detection $272 \mathrm{~nm}, \mathrm{t}_{\mathrm{R}} 11.2 \mathrm{~min}$ ). The following chromatographic system was used for preparative HPLC: Quaternary Gradient Module 2545, UV/Visible Detector 2489, and Fraction Collector III (Waters, Milford, MA, USA). ${ }^{1} \mathrm{H}$ and ${ }^{13} \mathrm{C}$ NMR spectra were recorded at 400 and $100 \mathrm{MHz}$, respectively, in $\mathrm{CDCl}_{3}$ as a solvent on a Bruker AVANCE III $400 \mathrm{MHz}$ spectrometer (Bruker, Karlshrue, Germany). The solvent residual signal ( $87.26 \mathrm{ppm})$ for ${ }^{1} \mathrm{H}$ NMR spectra and the carbon signal of $\mathrm{CDCl}_{3}(\delta 77.16 \mathrm{ppm})$ for ${ }^{13} \mathrm{C}$ NMR spectra were used as references. ESI-MS spectra were recorded with a TSQ Quantum Access spectrometer (Thermo Scientific, Waltham, MA, USA) after HPLC as described in Section 2.3. The spectral and spectroscopy data are given in the Supplementary Information. TeA was identified using literature data [22].

Tenuazonic acid: ESI-MS m/z $198.02[\mathrm{M}+\mathrm{H}]^{+} ;{ }^{1} \mathrm{H}$ NMR, predominant form: $6.77 \mathrm{br.s}$ $(\mathrm{NH}), 3.8 \mathrm{~d}(3.5 \mathrm{~Hz}), 2.47 \mathrm{~s}, 1.98 \mathrm{~m}, 1.40 \mathrm{~m}, 1.25 \mathrm{~m}, 1.03 \mathrm{~d}(7.0 \mathrm{~Hz}), 0.97 \mathrm{t}(7.35 \mathrm{~Hz}) ;$ minor form: 6.65 br.s $(\mathrm{NH}), 3.97 \mathrm{~d}(3.8 \mathrm{~Hz}), 2.52 \mathrm{~s}, 1.98 \mathrm{~m}, 1.41 \mathrm{~m}, 1.31 \mathrm{~m}, 1.03 \mathrm{~d}(7.0 \mathrm{~Hz}), 0.97 \mathrm{t}$ (7.35 Hz); ${ }^{13} \mathrm{C}$ NMR, predominant form: 195.4, 184.4, 176.3, 102.5, 67.1, 37.3, 23.7, 19.7, 15.8, 11.7; minor form: 201.1, 189.0, 169.8, 106.0, 63.8, 37.1, 24.0, 20.6, 15.4, 11.7.

\subsection{Bioassays}

\subsubsection{Entomotoxic Activity of Extracts}

The toxicity of A. tenuissima extracts was evaluated against the spring green aphid (Schizaphis graminum) and greater wax moth (Galleria mellonella) supplied by the Laboratory of Biological Control at the All-Russian Institute of Plant Protection. S. graminum was reared on wheat seedlings at $25 \pm 1{ }^{\circ} \mathrm{C}$ and $65 \pm 5 \%$ relative humidity, while G. mellonella was kept in the dark at $30^{\circ} \mathrm{C}$ in plastic boxes with perforated lids filled with artificial feed ( $90 \mathrm{~g}$ corn grits, $40 \mathrm{~g}$ wheat flour, $50 \mathrm{~g}$ milk powder, $10 \mathrm{~g}$ yeast, $50 \mathrm{~g}$ glycerol, $50 \mathrm{~g}$ beeswax, $50 \mathrm{~mL}$ water). Prior to the bioassays, the extracts samples were dissolved in ethanol, and then the solutions were adjusted with water to an extract concentration of $5 \mathrm{mg} / \mathrm{mL}$, while the final concentration of ethanol was $5 \%(v / v)$.

The contact intestinal aphicidal bioassay was described in detail earlier [23]. Briefly, filter paper disks ( $4 \mathrm{~cm}$ in diameter) placed on the bottom of a Petri dish were moistened with $0.5 \%$ extracts $\left(250 \mu \mathrm{L}\right.$ per disk or $\left.1 \mathrm{mg} / \mathrm{dm}^{2}\right)$. Segments of wheat leaves $(2 \mathrm{~cm}$ length) were dipped in the same test solutions and were placed on the filter paper. In the control treatment, $5 \%$ aqueous ethanol $(v / v)$ was used. Twenty aphids were transferred to each Petri dish. The mortality percentage of tested insects was recorded $24 \mathrm{~h}$ post-treatment under the above-mentioned conditions. Four replicates were made for each extract.

For the evaluation of the acute contact larvicidal activity of the extracts, the injection method was used as described previously [24] with slight modifications. Briefly, $10 \mu \mathrm{L}$ of $0.5 \%$ extracts were injected into the hemocoel via the third segment of IV-V instar G. mellonella larvae (190-230 mg each) with a Hamilton syringe. As a control treatment, 5\% aqueous ethanol $(v / v)$ was used. After the extract injection, the larvae were placed in a $90 \mathrm{~mm}$ sterile Petri dish supplemented with $2 \mathrm{~g}$ of artificial feed and were incubated in the dark for 10 days to record mortality daily. Twenty G. mellonella larvae were tested per treatment, and the experiment was repeated twice.

\subsubsection{Phytotoxic Activity of Extracts}

The phytotoxic activity of the extracts was assayed using the previously described method [25]. Leaf discs (1 cm in diameter) of perennial sowthistle (Sonchus arvensis) and leaf segments ( $2 \mathrm{~cm}$ length) of wheat (Triticum aestivum) were placed in a wet chamber and accurately punctured by a sharp needle. A $10 \mu \mathrm{L}$ droplet of $0.5 \%$ extract prepared in $5 \%$ ethanol was placed above the puncture. In the control treatment, $5 \%$ aqueous ethanol was used. The phytotoxic activity was determined as the diameter or length of necrotic 
lesions (for sowthistle and wheat, respectively) after $48 \mathrm{~h}$ of exposure at $24{ }^{\circ} \mathrm{C}$ and a $12 \mathrm{~h}$ photoperiod. Six leaf disks/segments were used for each treatment.

\subsubsection{Cytotoxic Activity of Extracts}

The cytotoxicity of A. tenuissima extracts was assayed on the Sf9 cell line (ECACC 89070101) originating from the ovarian tissue of the fall armyworm (Spodoptera frugiperda) maintained in the Laboratory of Molecular Plant Protection at the All-Russian Institute of Plant Protection. Samples $(10 \mu \mathrm{L})$ of assayed extracts dissolved in dimethyl sulfoxide (DMSO) to a concentration of $10 \mathrm{mg} / \mathrm{mL}$ were added to $890 \mu \mathrm{L}$ of fresh SF900II culture medium (Thermo Fisher Scientific, Waltham, MA, USA) and $100 \mu \mathrm{L}$ of a suspension of actively growing cells $\left(1 \times 10^{5}\right.$ cells $/ \mathrm{mL}$, viability $\left.\geq 90 \%\right)$ in wells of a 48 -well plate. The final concentration of the solvent was 1\%. A $1 \%$ DMSO solution was used as a control treatment. The cells were incubated for $24 \mathrm{~h}$ at $27^{\circ} \mathrm{C}$ and were then stained with $0.4 \%$ aqueous solution of trypan blue to count the percentage of dead (stained) cells in relation to the total number (at least 50) in several fields of view. Three replicates were used for each extract.

\subsubsection{Antimicrobial Activity of Extracts}

The antimicrobial activity of A. tenuissima extracts was tested against Bacillus subtilis NCTC 104000 and Candida albicans NCPF 3179 using the paper disk agar diffusion assay [26]. The microorganisms were grown on PDA. The samples of assayed extracts were dissolved in acetone and applied to the $6 \mathrm{~mm}$ paper discs (Macherey-Nagel, Düren, Germany) at a concentration of $500 \mu \mathrm{g} /$ disk. The treated microbial cultures were incubated at $30{ }^{\circ} \mathrm{C}$ for $24 \mathrm{~h}$ before the activity was determined as the radius of the growth inhibition zone in $\mathrm{mm}$. Three replicates were used for each extract.

\subsubsection{Insect Models and TeA}

G. mellonella larvae and S. graminum females were prepared as described in Section 2.5.1. The Zophobas morio laboratory population was reared in trays with wheat bran and fruit peelings. The colony of house cricket (Acheta domesticus) was reared in plastic boxes filled with carton pieces and fruit peelings. The population of the two-spotted spider mite (Tetranychus urticae) was grown on common bean (Phaseolus vulgaris) seedlings. All arthropods were obtained from the abovementioned laboratory of biological control.

The samples of TeA were dissolved in ethanol for bioassays as described above. The analytical standard (Sigma-Aldrich, St. Louis, MO, USA) of the entomotoxic fungal metabolite beauvericin was used as a positive control in some bioassays in the same way as TeA.

\subsubsection{Acute Contact Toxicity of TeA}

An injection test was performed using the IV-V instar larvae of G. mellonella (190-230 mg each) and Z. morio (135-150 mg each); the procedure was similar to that described in Section 2.5.1. The concentrations of TeA solutions for injection were 0.5, 1, 2, and $5 \mathrm{mg} / \mathrm{mL}$. After injection, test insects were placed in sterile Petri dishes supplemented with $2 \mathrm{~g}$ of feed (the artificial feed for G. mellonella and a piece of zucchini for Z. morio) and incubated in darkness at $30^{\circ} \mathrm{C}$ for ten days. The mortality and weight of treated larvae were recorded daily. Five larvae were tested as a group within the experiments, and four replicates were performed.

\subsubsection{Oral Toxicity of TeA}

G. mellonella larvae and A. domesticus adults were subjected to a diet containing different concentrations of TeA. A bioassay was conducted by dissolving TeA in acetone and adding it to food samples (artificial feed for G. mellonella and a piece of zucchini for A. domesticus) at concentrations of $0.25,1.0$, and $2.5 \mathrm{mg} / \mathrm{g}$. The control was treated with the same volume of acetone. The solvent was evaporated from treated feed samples at room 
temperature for $45 \mathrm{~min}$. Beginning on the second day of the experiment, the feed samples were replaced with fresh ones every two days. Ten larvae of G. mellonella were tested as a group within the experiments, and two replicates were performed. Ten $A$. domesticus adults were tested per replicate, and four replicates were performed. The insects were incubated for 10 days in darkness. The mortality and weight of the insects were recorded daily.

\subsubsection{Contact Intestinal Toxicity of TeA}

Aphicidal activity of TeA was tested against the wheat aphid as described above (Section 2.5.1) at concentrations of $0.5,1.0$, and $2.0 \mathrm{mg} / \mathrm{mL}\left(100,200\right.$, and $\left.400 \mu \mathrm{g} / \mathrm{dm}^{2}\right)$. The acaricidal effects of TeA were tested against the mite T. urticae at the same concentrations, similar to a published technique [27]. Common bean leaf discs (diameter of $4 \mathrm{~cm}$ ) were dipped for $2 \mathrm{~s}$ in the toxin solutions. After liquid evaporation, the leaf discs were placed in a glass Petri dish (diameter of $9 \mathrm{~cm}$ ) on filter paper moistened with water. In the control treatment, leaf discs were dipped in 5\% ethanol as described above. Twenty T. urticae females were introduced to each leaf replicate disc, and five replicates were performed.

\subsubsection{Cytotoxic Activity of TeA}

Sf9 cells were used for TeA cytotoxicity assessment at a concentration range of $1-100 \mu \mathrm{g} / \mathrm{mL}$, as described in Section 2.5.3.

\subsection{Statistical Analysis}

Statistical analysis was performed using Statistica 10 (StatSoft, Tusla, OK, USA) and SigmaPlot 14 (Systat Software, San Jose, CA, USA) software. Data normality was determined by the Shapiro-Wilk W test. The values expressed as percentages (\%) were transformed ( $\mathrm{g}$ or square root) before the tests. Normally distributed data were analyzed using one- or two-way analysis of variance (ANOVA) depending on the experimental setup. Pairwise comparison was performed by Tukey's HSD test at a significance level of $p=0.05$. In the absence of a normal distribution, the data were analyzed by methods of nonparametric statistics. The significance of the factor effects was determined using a Kruskal-Wallis H-test (one-way ANOVA on ranks), and significant differences between the median values were determined by Dunn's post hoc test. The survival rate of arthropods under the influence of TeA was determined by log-rank test with Holm-Sidak adjustment. $\mathrm{IC}_{50}$ values representing TeA concentration required to cause a $50 \%$ reduction in Sf9 cells viability were determined by the SigmaPlot curvilinear regression procedure.

\section{Results}

\subsection{The Yield of A. tenuissima Extracts}

The results of two-way ANOVA showed that the composition of the nutrient medium $\left(\mathrm{F}_{3,16}=6.1, p=0.01\right)$ and the extraction solvent $\left(\mathrm{F}_{1,16}=79.8, p=0.001\right)$ significantly affected the yield of extractive matter (YEM) from the culture filtrate of A. tenuissima MFP253011. The interaction of both factors was also significant $\left(\mathrm{F}_{3,16}=4.4, p=0.02\right)$. The YEM from the fungal culture filtrate cultivated on MCM was almost three times lower than those grown on other liquid media. When sequentially extracted with DCM and EtOAc, the YEM was on average seven times higher in EtOAc extracts than in DCM extracts. The maximum yield of DCM extracts (about $200 \mathrm{mg} / \mathrm{L}$ ) was obtained by growing the fungus on SAB medium. YEM of EtOAc extracts was maximal when YMG medium (more than $640 \mathrm{mg} / \mathrm{L}$ ) was used (Figure 1). 


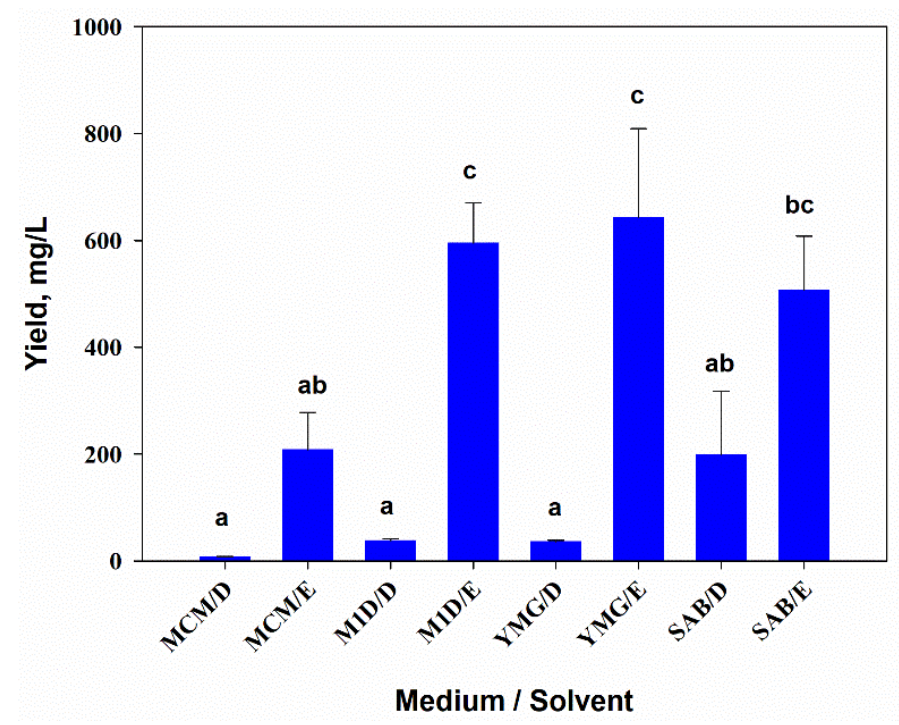

Figure 1. Yield of extractive matter from the filtrate of Alternaria tenuissima MFP253011 cultures on various liquid media obtained by successive extractions with dichloromethane (D) and ethyl acetate (E). Means \pm standard deviation $(n=3)$ marked with the same letter did not differ significantly at the level of $p=0.05$ according to Tukey's HSD test.

When the fungus was cultured on pearl barley, the yield of the hexane extracts was $408.3 \pm 40 \mathrm{mg} / \mathrm{kg}$, while EtOAc extracts yielded $1740.3 \pm 49.8 \mathrm{mg} / \mathrm{kg}$.

\subsection{The Spectrum of Biological Activity of A. tenuissima Extracts}

\subsubsection{Entomotoxic Activity}

The results of one-way ANOVA showed that the composition of the substrate and the extraction solvent as a combined factor had a significant $\left(\mathrm{F}_{10,33}=25.37, p=0.01\right)$ effect on the aphicidal activity of $A$. tenuissima MFP253011 extracts. The maximum activity against S. graminum ( $>80 \%$ mortality $24 \mathrm{~h}$ post-treatment) was shown by the DCM extract from the filtrate of the A. tenuissima culture on the M1D medium. The common wheat aphid was nonsignificantly (at $p=0.05$ ) less sensitive to the DCM extract from the filtrate of the A. tenuissima culture on SAB ( $~ 70 \%$ mortality) and the EtOAc extract from the solid culture of the fungus ( $>60 \%$ mortality). Hexane extract from the solid culture of A. tenuissima also had aphicidal activity $(\sim 50 \%$ mortality) that was significantly (at $p=0.05)$ different from the control values. The sensitivity of the common wheat aphid to other extracts was low ( $\leq 25 \%$ mortality) and did not differ from the control at $p=0.05$ (Figure 2A).

The composition of the nutrient medium for growing A. tenuissima and the extraction method had a significant effect (one-way ANOVA, $\mathrm{F}_{9,10}=7.35, p=0.01$ ) on the toxicity of extracts to G. mellonella larvae. Most of the dead larvae were melanized 3-4 days post treatment. No larvae died in the untreated control by the 7th day of observation. A high level of larvicidal activity ( $\geq 75 \%$ mortality 7 days post-treatment), which was significantly different from the control at $p=0.05$, was demonstrated by the EtOAc extracts from the cultures produced on various liquid (M1D, YMG, SAB) and solid substrates. Among the DCM extracts, the maximum toxicity (only 30\% larval mortality), which differed from the control at $p=0.05$, demonstrated an extract from culture liquid on M1D. In the remaining extracts, the larvicidal activity was noticeably low, the mortality rate was below $30 \%$. No larvae were affected in the control (Figure 2B).

\subsubsection{Phytotoxic Activity}

All the evaluated extracts of A. tenuissima were toxic to leaf segments of both wheat and perennial sowthistle. At the same time, the medium composition combined with the extraction solvent had a significant $(p=0.001)$ effect on phytotoxic activity of the fungal extracts for wheat $\left(\mathrm{H}_{9,50}=49.1\right)$ and sowthistle $\left(\mathrm{H}_{9,50}=45.9\right)$ segments according 
to Kruskal-Wallis one-way ANOVA on ranks. The EtOAc extracts from the filtrate of A. tenuissima cultures grown on M1D, YMG, and SAB media showed relatively high activity on the leaf segments of both plants. No phytotoxicity symptoms were found in the control treatments.

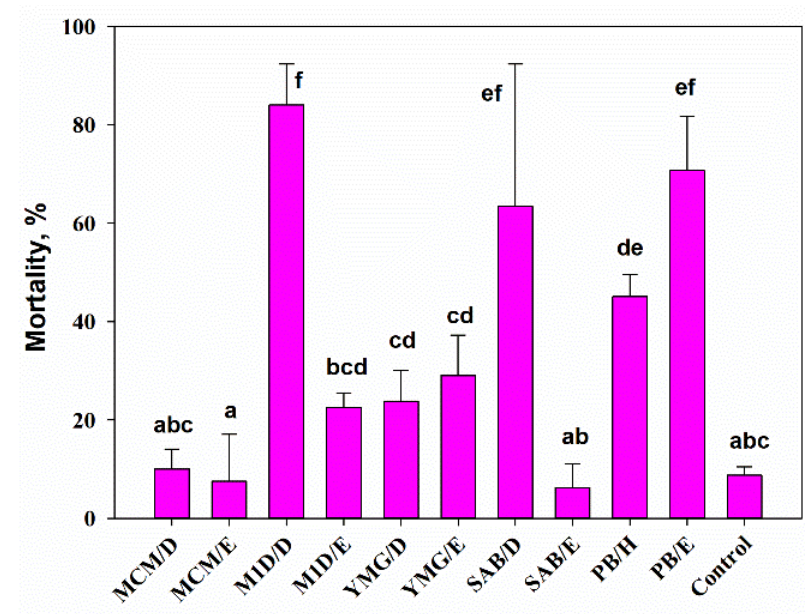

Medium / Solvent

(A)

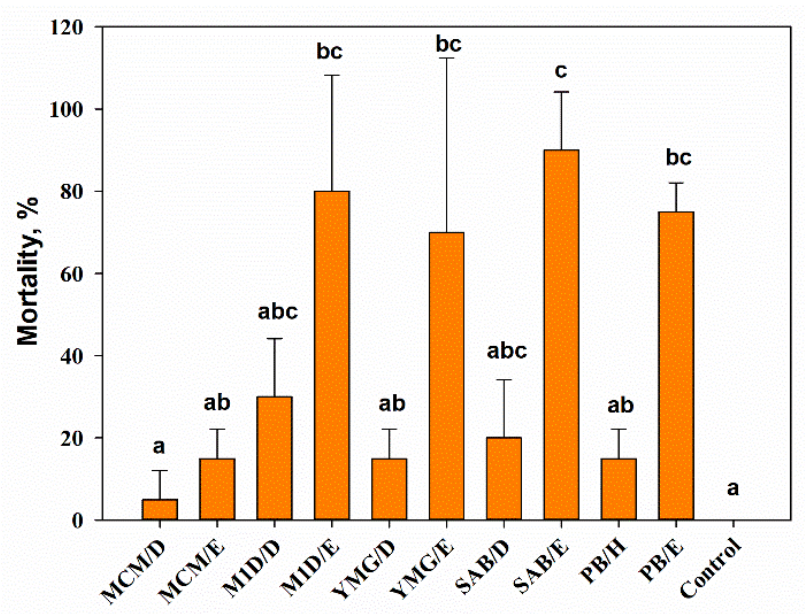

Medium / Solvent

(B)

Figure 2. Entomotoxic activity of extracts from Alternaria tenuissima MFP253011 cultures on various liquid and solid nutrient substrates on Schizaphis graminum at a concentration of $5 \mathrm{mg} / \mathrm{mL} 24 \mathrm{~h}$ post treatment (A) and on Galleria mellonella at a concentration of $50 \mu \mathrm{g}$ / larva 7 days post treatment (B). Means \pm std. deviation marked with the same letter did not differ significantly at the level of $p=0.05$ according to Tukey's HSD test. D—dichloromethane, E—ethyl acetate, H—hexane.

The leaf discs of sowthistle were highly sensitive (necrosis diameter 7-9 $\mathrm{mm}$ ) to EtOAc extracts from A. tenuissima cultures grown on most of the used substrates, with the exception of MCM. DCM extracts from culture liquid and hexane extract from solid culture were generally less toxic; the diameter of necrosis was in the range of 3-5 mm (Figure 3A). The EtOAc extract from the filtrate of culture on YMG was significantly more toxic compared with the DCM extract from the culture liquid produced on M1D medium $(p=0.002)$ and the DCM $(p=0.03)$ and EtOAc extracts from cultures on MCM $(p=0.021)$.

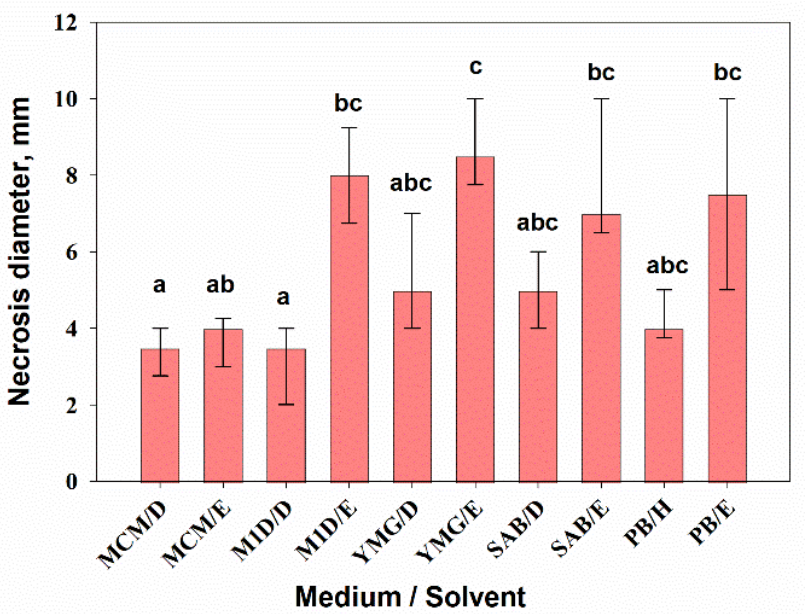

(A)

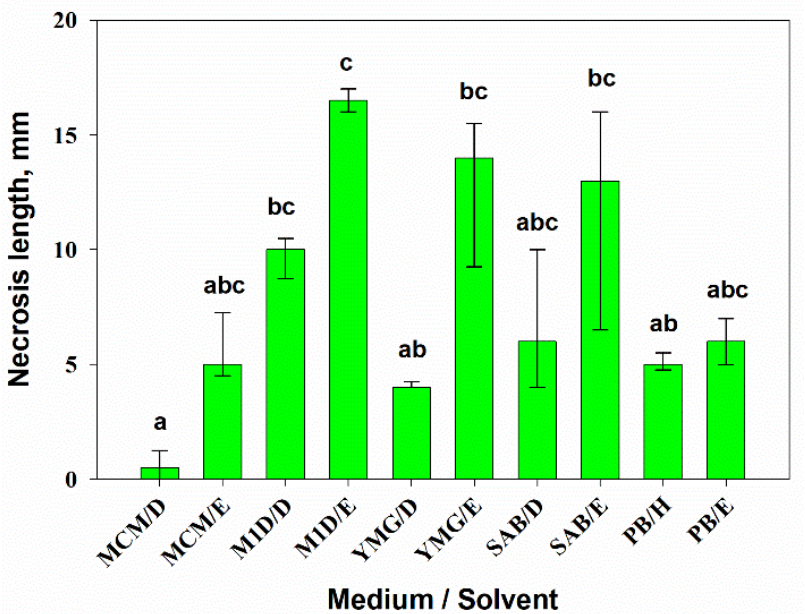

(B)

Figure 3. Phytotoxic activity of $0.5 \%$ extracts from Alternaria tenuissima MFP253011 cultures grown on various liquid and solid media $48 \mathrm{~h}$ post-treatment assayed on leaf discs of Sonchus arvensis (A) and leaf segments of Triticum aestivum (B). Median values with 25-75\% quartiles marked with the same letter did not differ significantly at the level of $p=0.05$ according to Dunn's test. D-dichloromethane, E- ethyl acetate, H-hexane. 
There were significant differences in sensitivity of wheat leaf segments to highly toxic EtOAc extract from the M1D liquid culture of $A$. tenuissima and three non-polar extracts: the DCM extracts from MCM $(p=0.001)$ and YMG $(p=0.01)$ liquid cultures as well as the hexane extract from PB solid culture $(p=0.03)$ (Figure 3B).

\subsubsection{Cytotoxic Activity}

Combining the medium composition and the extraction method had a significant effect $\left(\mathrm{H}_{10,33}=41.9, p=0.001\right)$ on the cytotoxicity of $0.01 \%$ extracts from $A$. tenuissima cultures according to Kruskal-Wallis one-way ANOVA on ranks. DCM extracts from the filtrate obtained from MCM and M1D liquid cultures, as well as hexane and EtOAc extracts from the solid (PB) culture of A. tenuissima, caused 100\% mortality of Sf9 cells. The cytotoxicity of the DCM extract from the YMG liquid culture was significantly lower $(p=0.014)$ than the toxicity of the mentioned extracts. The EtOAc extracts from the filtrate obtained from MCM and M1D liquid cultures and the DCM extract from the filtrate of fungal liquid cultures grown on SAB were moderately toxic (50-60\% cell mortality). EtOAc extracts from the filtrate of fungal liquid cultures grown on semi-synthetic YMG and SAB media were weakly toxic (up to $20 \%$ cell mortality) (Figure 4 ).

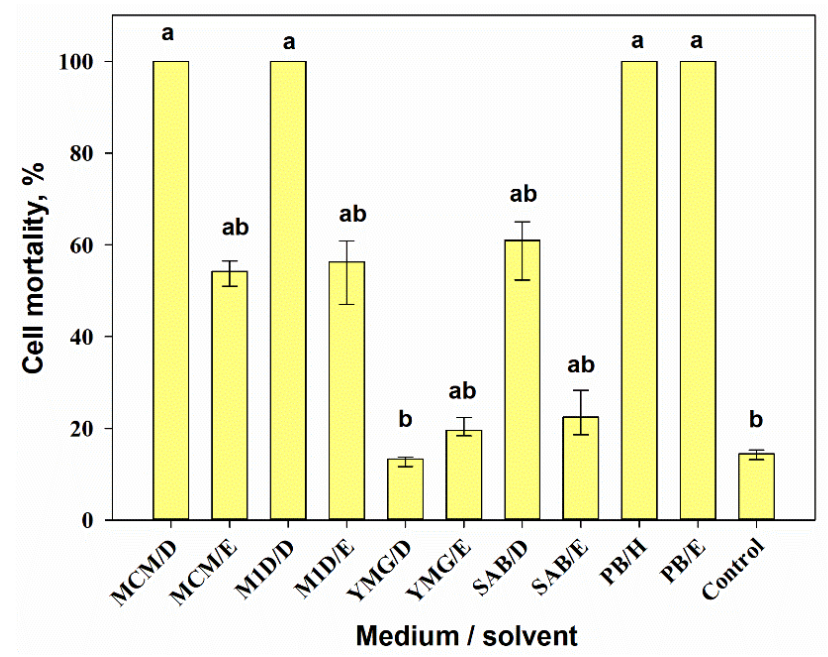

Figure 4. Cytotoxic activity of $0.01 \%$ extracts from Alternaria tenuissima MFP253011 cultures grown on various liquid and solid media $24 \mathrm{~h}$ post-treatment assayed on Sf9 cells. Median values with $25-75 \%$ quartiles marked with the same letter did not differ significantly at the level of $p=0.05$ according to Dunn's test. D-dichloromethane, E-ethyl acetate, $\mathrm{H}$-hexane.

\subsubsection{Antimicrobial Activity}

The medium composition and the extraction method had significant effects (oneway ANOVA, $\mathrm{F}_{9,20}=107.6, p=0.001$ ) on the antibacterial activity of A. tenuissima extracts against the gram-positive bacterium Bacillus subtilis. The highest inhibitory activity (10-12 mm lysis zone) was shown by EtOAc extracts $(500 \mu \mathrm{g} /$ disc $)$ from A. tenuissima cultures grown on M1D and YMG media as well as on the solid substrate. The bacterium was also moderately sensitive to DCM extracts from the culture fluid of the fungus on M1D and YMG media (the radius of the lysis zone was 7-9 $\mathrm{mm}$ ) (Figure 5). These two extracts considerably suppressed the growth of C. albicans (9-11 mm lysis zone), while the activity of others was insignificant (data not shown). 


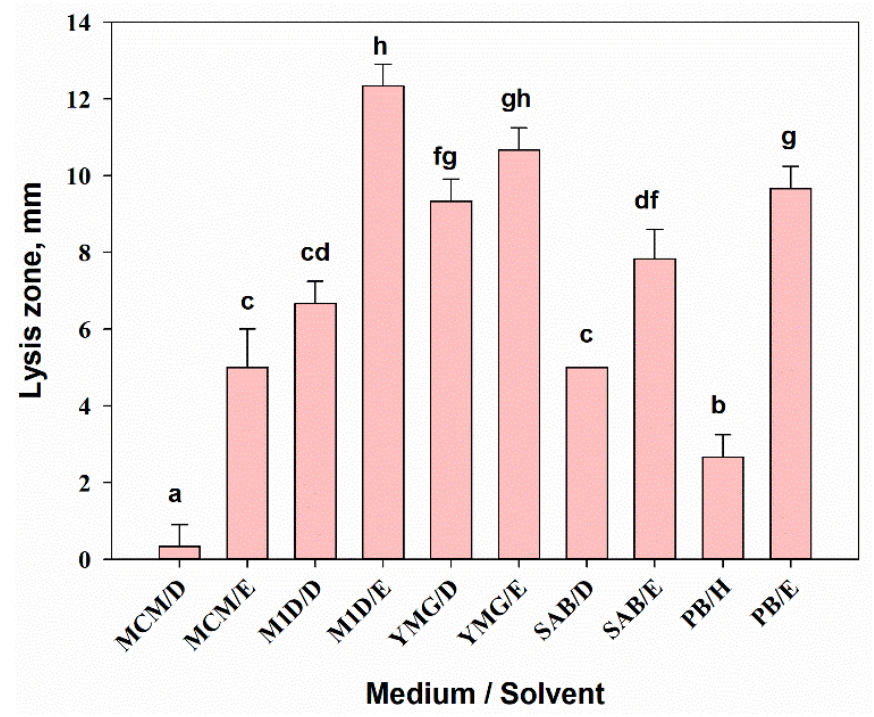

Figure 5. Antibacterial activity of extracts from Alternaria tenuissima MFP253011 cultures grown on various liquid and solid media $24 \mathrm{~h}$ post-treatment against Bacillus subtilis. Means $\pm \mathrm{std}$. deviation marked with the same letter did not differ significantly at the level of $p=0.05$ according to Tukey's HSD test. D—dichloromethane, E-ethyl acetate, $\mathrm{H}$ - hexane.

\subsection{Analysis of Extracts}

In the extracts from the culture liquid of A. tenuissima MFP253011, three known mycotoxins (tentoxin, dihydrotentoxin, and tenuazonic acid) were detected by characteristic MSand UV-spectra. Another group of substances presumably belonged to the meroterpenoid group, such as ACTG toxins and tricycloalternarenes (chromatography peaks with $\mathrm{m} / \mathrm{z}$ $321,345,349,363$, and 377 and a typical 266-272 nm single UV-absorption band). Their exact identification in the extracts is difficult because of the presence of isomers [28-32].

Three tricycloalternarene (TCA) compounds with an mw of $348 \mathrm{Da}$ (presumably isomers of TCA 1) and $362 \mathrm{Da}$ (presumably TCA $11 \mathrm{a} / \mathrm{b}$ ) as well as a polypeptide (presumably iso-tentoxin with an mw of $414 \mathrm{Da}$ ) were identified as major metabolites in the DCM extract from fungal culture on M1D liquid medium (Figure 6A), which showed aphicidal and other types of activity (Figure 2A).

When A. tenuissima was cultured on semi-synthetic YMG and SAB media, tentoxin and dihydrotentoxin prevailed in DCM extracts from the culture liquid. The latter extract was more complex and contained two TCAs (presumably TCA $4 \mathrm{a} / \mathrm{b}$ and TCA $5 \mathrm{a} / \mathrm{b}$ ) with an mw of $344 \mathrm{Da}$ (Figure 6B) and showed aphicidal activity (Figure 2A).

In the EtOAc extracts of $A$. tenuissima, which were highly toxic to G. mellonella larvae (Figure 2B), the major metabolite was tenuazonic acid. Its relative content was high in the extracts from the filtrate of cultures on M1D, YMG, and SAB media, while the EtOAc extract from the solid culture had a relatively lower concentration of the toxin because of the presence of other compounds, such as two substances with mw $320 \mathrm{Da}$ (presumably, TCA A isomers) (Figure 6C,D).

Data on the biological activity of 10 extracts on nine test organisms and the relative content of nine major metabolites in them were evaluated with PCA. Three principal components (PC) were revealed, which explained $40.1,18.5$, and $12.6 \%$ of the data variance, respectively; the effect of the remaining seven components to explain the data was not significant. 


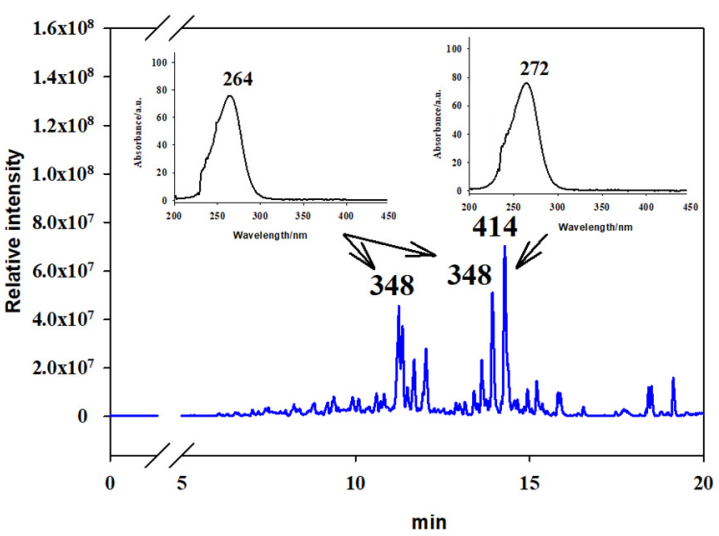

(A)

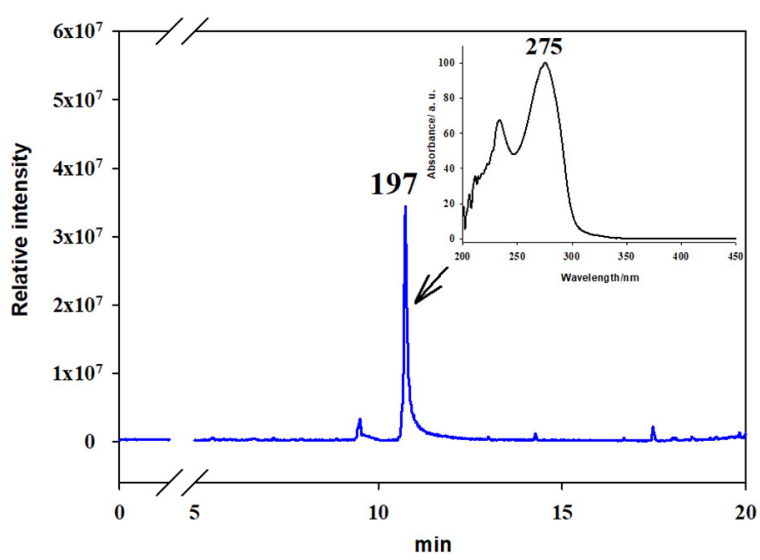

(C)

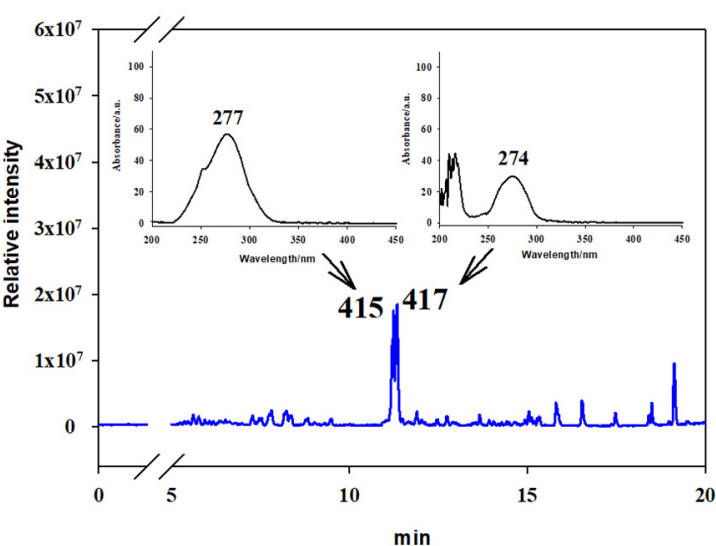

(B)

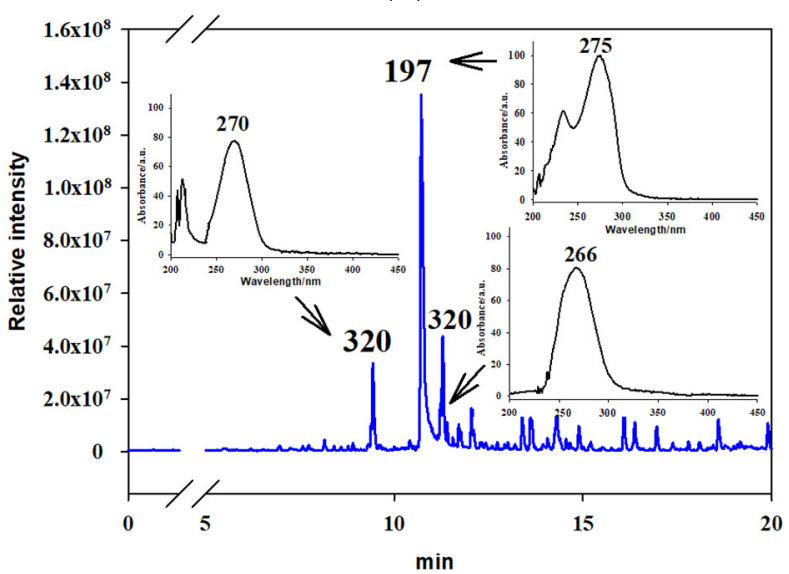

(D)

Figure 6. Representative HPLC/MS chromatograms of extracts showing entomotoxic activity from Alternaria tenuissima MFP253011 cultures on various media obtained with dichloromethane (A) M1D medium, (B) Sabouraud medium and ethyl acetate, (C) YMG medium, and (D) pearl barley.

Analyzing PC1 and PC2, it was found that the sensitivity of the common wheat aphid $S$. graminum and the infusoria $P$. caudatum to some extracts may be associated with the content of tentoxin and dihydrotentoxin (see cluster A in Figure 7A). In the PC1 and PC3 coordinates, the aphicidal and cytotoxic activity of the extracts seemed to be associated with the presence of the metabolites with molecular weights of 338, 348, and $362 \mathrm{Da}$ (see cluster A on Figure 7B). The sensitivity of G. mellonella larvae to the extracts was closely correlated with the content of tenuazonic acid (TeA) (see cluster B in Figure 7A,B).

The sensitivity of Sf 9 cells appeared to be correlated with TCA content in the extracts (cluster C in Figure 7A, cluster A in Figure 7B).

Considering the relatively high yield of EtOAc extracts (Figure 1), TeA was found to be the main easily available exo-metabolite in the liquid cultures of A.tenuissima MFP253011 grown on M1D and YMG media. Because these extracts demonstrated relatively high toxicity to G. mellonella larvae, TeA was purified from them to confirm the entomotoxic activity.

\subsection{Entomotoxic Activity of Tenuazonic Acid}

\subsubsection{Acute Contact Larvicidal Toxicity}

G. mellonella larvae were sensitive to the injection of $\mathrm{TeA}$ in the tested concentrations. The dead caterpillars became melanized. A statistically significant difference between the survival curves was revealed (log-rank test: $\left.\chi^{2}=15.5, \mathrm{df}=4, p=0.004\right)$. At concentrations of $20 \mu \mathrm{g} /$ larva ( $\mathrm{LT}_{50}=6 \pm 1.3$ days) and $50 \mu \mathrm{g} /$ larva ( $\mathrm{LT}_{50}=6 \pm 0.8$ days), TeA significantly (at $p=0.05$ ) decreased the survival rate of $G$. mellonella larvae compared with the control (Figure 8A). 


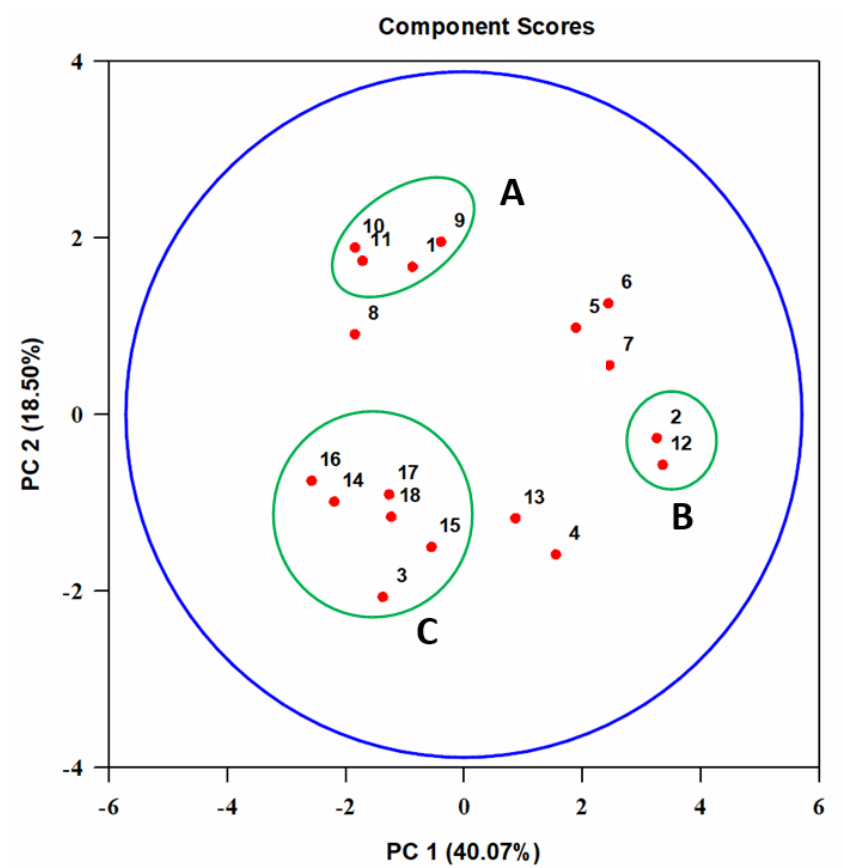

(A)

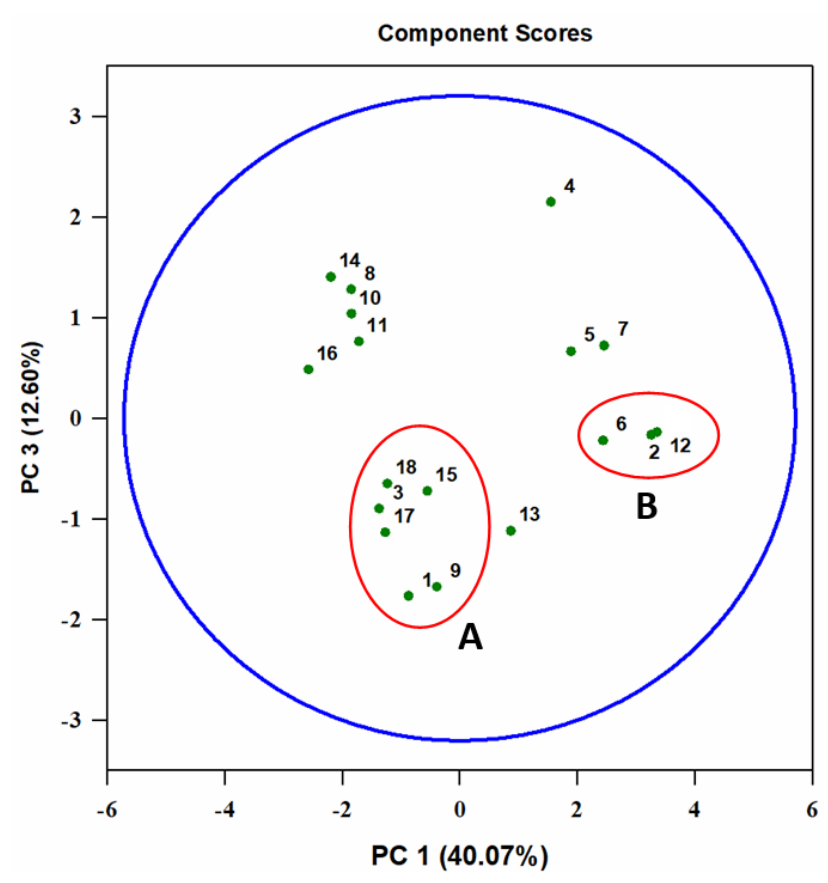

(B)

Figure 7. Principal component (PC) analysis (A)-PC1 vs. PC2, (B)-PC1 vs. PC3 on the relationship between the sensitivity of various organisms to different $A$. tenuissima MFP253011 extracts and the contents of major metabolites in them. Test organisms: 1-Schizaphis graminum, 2-Galleria mellonella, 3-Sf9 cell line, 4-Raphanus sativus, 5-Triticum aestivum, 6-Sonchus arvensis, 7-Bacillus subtilis, 8-Candida albicans, 9-Paramecium caudatum. Analyzed compounds (molecular weight, Da): 10 —tentoxin (414), 11-dihydrotentoxin (416), 12-tenuazonic acid (197), 13-unidentified (320), 14-unidentified (328), 15-unidentified (338), 16-unidentified (344), 17-unidentified (348), 18-unidentified (362).

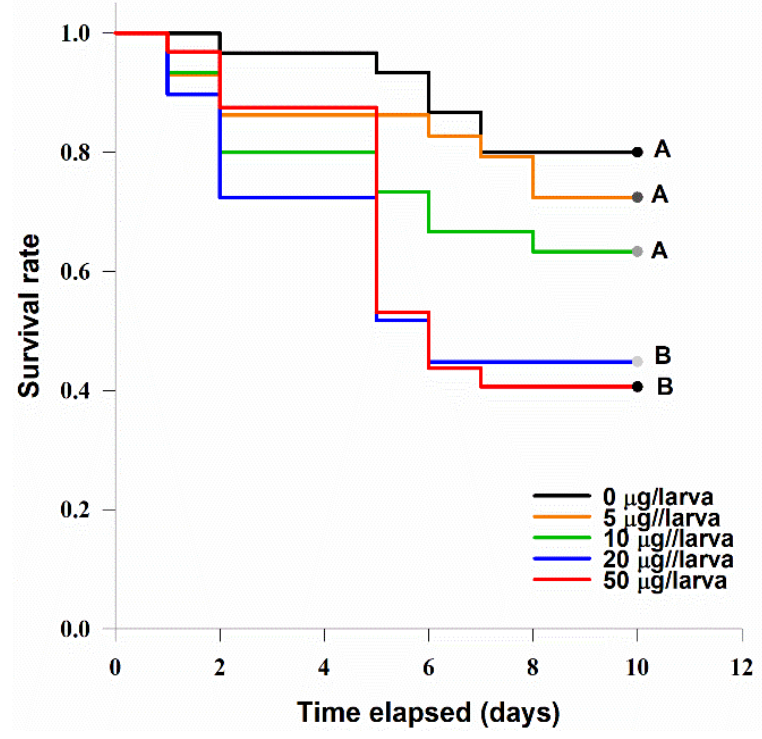

(A)

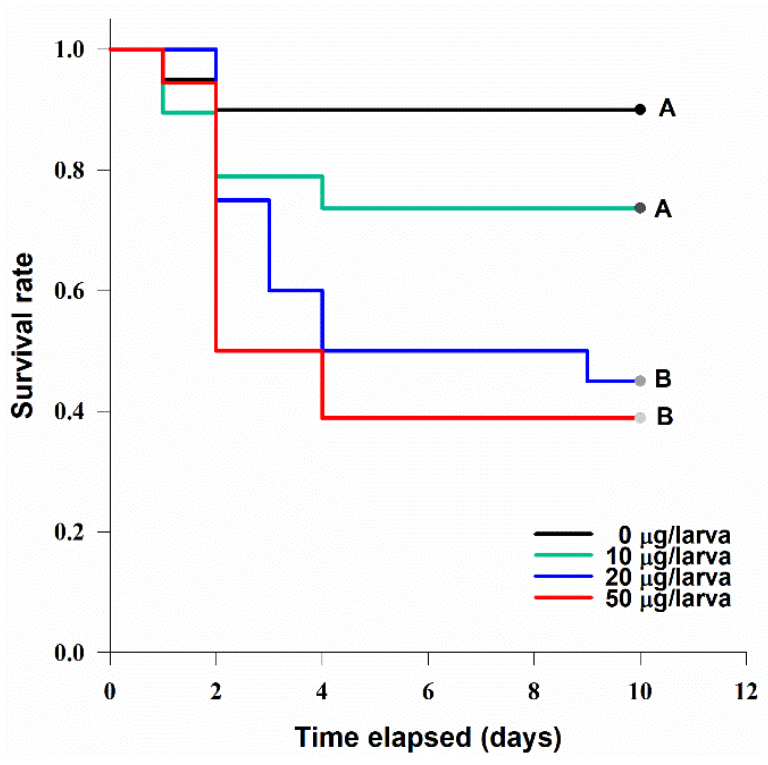

(B)

Figure 8. Survival curves of Galleria mellonella (A) and Zophobas morio (B) larvae after injection with various concentrations of tenuazonic acid. The curves marked with one letter did not differ significantly at $p=0.05$ by log-rank test with Holm-Sidak adjustment. 
Zophobas morio larvae were also sensitive to the injection of various concentrations of TeA (Figure 8B). There was a statistically significant difference between the survival curves (log-rank test: $\chi^{2}=12.7, \mathrm{df}=3, p=0.005$ ). At concentrations of $20 \mu \mathrm{g} /$ larva $\left(\mathrm{LT}_{50}=4 \pm 4.5\right.$ days$)$ and $50 \mu \mathrm{g} /$ larva $\left(\mathrm{LT}_{50}=2 \pm 0.6\right.$ days), TeA significantly (at $\left.p=0.05\right)$ decreased the survival rate of $Z$. morio larvae compared with the control.

\subsubsection{Oral Toxicity}

Two-way ANOVA of the lg-transformed data showed that TeA concentration in the artificial feed strongly $\left(\mathrm{F}_{4,30}=70.1, p<0.001\right)$ affected the biomass of $G$. mellonella larvae, while the time factor was insignificant $\left(\mathrm{F}_{5,30}=1.4, p=0.25\right)$. The interaction of the factors "time" and "TeA concentration" was significant $\left(\mathrm{F}_{20,30}=6.4, p<0.001\right)$, indicating the existence of different trends. A significant (at $p=0.05$ ) decrease of larvae biomass accumulation compared with the control was noted at a TeA concentration of $2.5 \mathrm{mg} / \mathrm{g}$ of the feed, starting from the 4 th day post-treatment; by the 10th day of observations, it became approximately two times lower than in the control. At a concentration of $0.25 \mathrm{mg} / \mathrm{g}$ of feed, the inhibitory effect of $\mathrm{TeA}$ was pronounced on the 6th day of the experiment (Figure 9). Visually, G. mellonella larvae refused to eat the feed containing TeA. This probably explains why their mortality did not exceed the level of $20 \%$ by the 10th day of observations at a TeA concentration of $25 \mathrm{mg} / \mathrm{g}$ of feed.

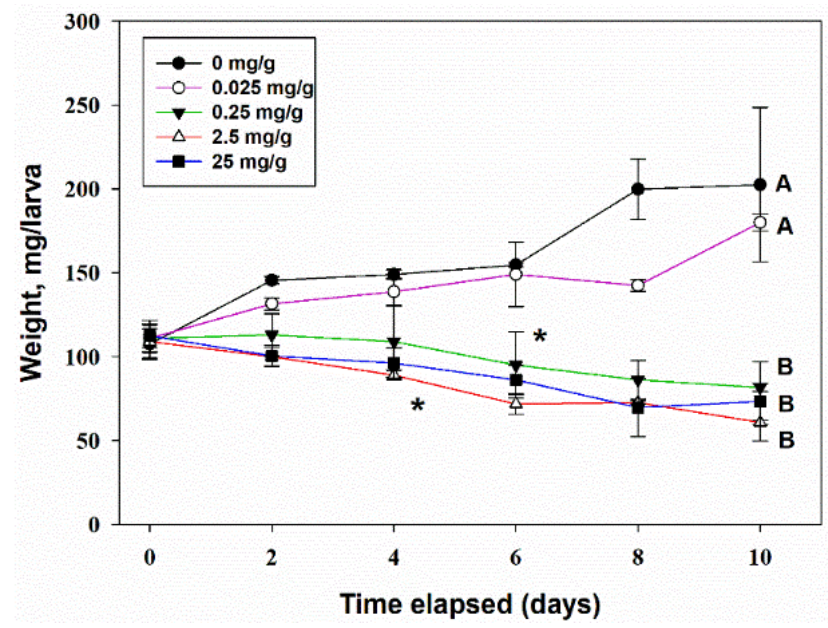

Figure 9. The effect of the concentration of tenuazonic acid in artificial feed on the growth of the biomass of Galleria mellonella larvae. Means \pm std. deviation marked with the same letter did not differ significantly at the level of $p=0.05$ according to Tukey's HSD test. *-significant difference from control at $p=0.05$ by Dunnett's test.

After 2 days of incubation, Acheta domesticus adults completely consumed the toxinspiked and control feed, and in all the treatments it was replaced with fresh (without the addition of TeA) feed. A statistically significant difference (log-rank test: $\chi^{2}=16.4, \mathrm{df} 3$, $p=0.001$ ) between the survival curves of the crickets fed with different TeA contents was revealed (Figure 10). The cricket mortality rate was significantly (at $p=0.05)$ higher than that of the control at all TeA concentrations used, but the differences between the treatment options were insignificant. The median survival of the cricket was $3 \pm 0.2,5 \pm 1.5$, and $7 \pm 0.9$ days at toxin concentrations of $2.5,1$, and $0.25 \mathrm{mg} / \mathrm{g}$ of feed, respectively. 


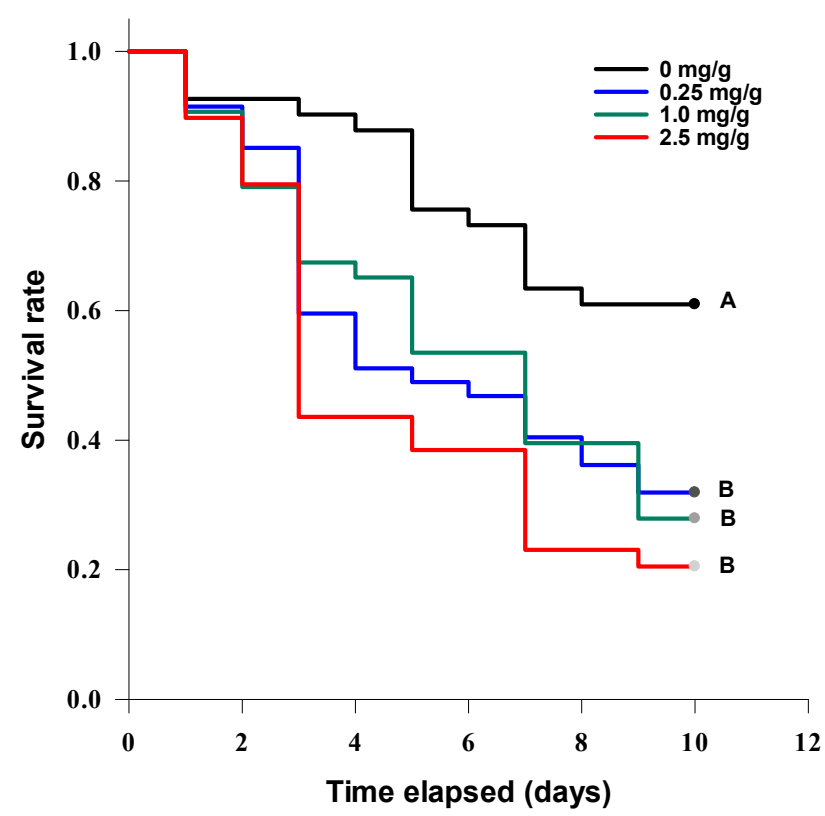

Figure 10. The survival curves of Acheta domesticus adults at different concentrations of tenuazonic acid added to the feed. The curves marked with one letter did not differ significantly at $p=0.05$ by log-rank test with Holm-Sidak adjustment.

\subsubsection{Contact Intestinal Activity}

The concentration of TeA had a significant (one-way ANOVA, $p=0.001$ ) effect on the mortality of the common wheat aphid $\left(\mathrm{F}_{3,8}=28.4\right)$ and female of spider mites $\left(\mathrm{F}_{3,16}=31.4\right)$ $24 \mathrm{~h}$ after treatment. Significant (at $p=0.05$ ) aphicidal activity of TeA was noted at a toxin concentration of $1.0 \mathrm{mg} / \mathrm{mL}$ ( $27 \%$ mortality), and acaricidal action was revealed at a concentration of $0.5 \mathrm{mg} / \mathrm{mL}$ (12\% mortality). At a maximal concentration of $2 \mathrm{mg} / \mathrm{mL}$, the mortality reached $43 \%$ and $19 \%$ for the aphids and mites, respectively (Figure 11A,B). Beauvericin caused $100 \%$ mortality of the tested arthropods at a concentration of $0.5 \mathrm{mg} / \mathrm{mL}$.

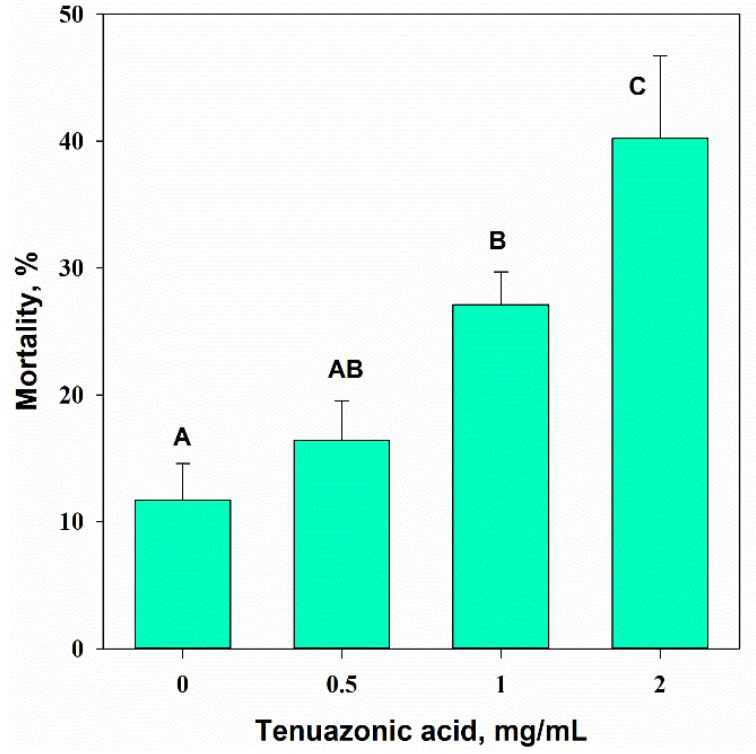

(A)

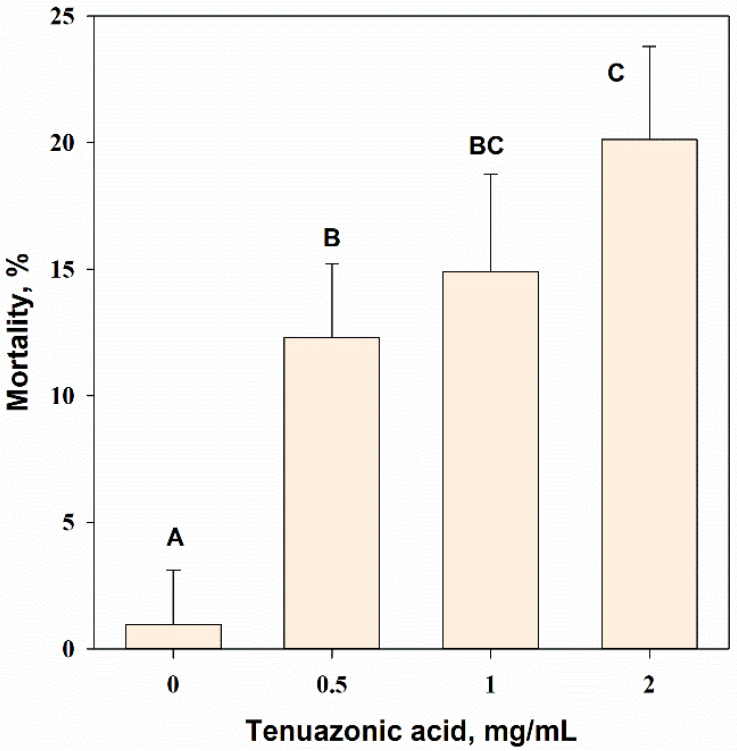

(B)

Figure 11. Toxicity of various concentrations of tenuazonic acid against Schizaphis graminum (A) and Tetranichus urticae (B) $24 \mathrm{~h}$ post treatment. Means $\pm \mathrm{std}$. deviation marked with the same letter did not differ significantly at the level of $p=0.05$ according to Tukey's HSD test. 
No symptoms of phytotoxicity were manifested on wheat leaf segments soaked in TeA solution, whereas small necrotic lesions (up to $10 \%$ of total leaf disc area) were noted on bean leaves at a TeA concentration of $2 \mathrm{mg} / \mathrm{mL} 24 \mathrm{~h}$ after treatment.

\subsubsection{Cytotoxic Activity}

TeA was approximately five times less toxic with $\mathrm{IC}_{50} 25 \mu \mathrm{g} / \mathrm{mL}(126 \mu \mathrm{M})$ than beauvericin with $\mathrm{IC}_{50} 4 \mu \mathrm{g} / \mathrm{mL}(5 \mu \mathrm{M})$ against Sf9 Spodoptera frugiperda cells. Unlike beauvericin, at all the studied concentrations, TeA caused rapid degradation of Sf9 cells. It should be noted that the exact calculation of the $\mathrm{IC}_{50}$ for $\mathrm{TeA}$ was difficult due to the fact that the dead cells were rapidly destroyed (Figure 12).
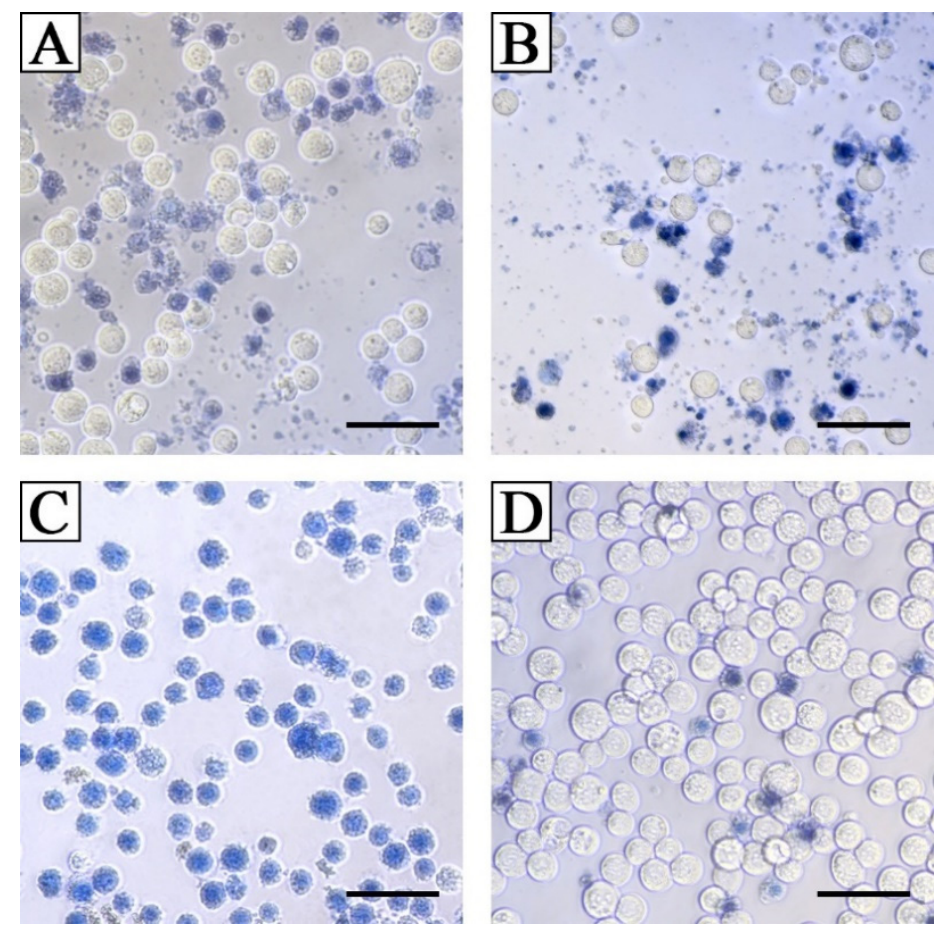

Figure 12. Morphology of Sf9 cells after $24 \mathrm{~h}$ of exposure with $15 \mu \mathrm{g} / \mathrm{mL}$ (A) and $25 \mu \mathrm{g} / \mathrm{mL}$ (B) of tenuazonic acid, and $25 \mu \mathrm{g} / \mathrm{mL}$ of beauvericin (C); (D) control (1\% DMSO). Bar indicates $50 \mu \mathrm{m}$.

\section{Discussion}

\subsection{Detection of Entomotoxic Metabolites in A. tenuissima Extracts}

Metabolites of small-spored Alternaria species have been characterized as mycotoxins (tenuazonic acid, alternariol and its methyl ester, altertoxins) and as substances with phytotoxic (e.g., altenuene, tenuazonic acid, tentoxin, and a number of host-specific toxins), antimicrobial (e.g., altersetin), cytotoxic activity (bi- and tricycloalternarenes), and other interesting properties (enzyme inhibitors, antioxidants, etc.). Many of them possess several types of biological activity [33-35]. In the present and earlier studies [21], the extracts from A. tenuissima MFP253011 cultures obtained by various methods (using different media and solvents) were found to display entomotoxic activity along with phytotoxic, antimicrobial, and cytotoxic properties (Figures 2-5). A number of known (tenuazonic acid, tentoxin, and dihydrotentoxin) and unidentified compounds belonging to the tricycloalternarene group were detected, but the composition of extracts varied depending on the production method (Figure 6). This allowed us to evaluate the relationship of the entomotoxic activity of A. tenuissima extracts with other bioactivity types together with the formation of nine major metabolites (Figure 7). A similar approach was successfully implemented to identify the determinants of the pathogenicity of Ilyonectria mors-panacis affecting ginseng [36] and the biological activity of the aquatic micromycete Aspergillus awamori [37]. 
Analysis of the composition of extracts and their activity by PCA revealed that the aphicidal activity of extracts was associated with the presence of tentoxin and dihydrotentoxin as well as some tricycloalternarenes (TCA), for example, TCA 1 a/b (mw 348 Da), TCA $11 \mathrm{a} / \mathrm{b}$ (mw $362 \mathrm{Da}$ ), and others (Figure 7). However, the entomotoxic activity of the compounds is unknown, while their cytotoxic activity has not been sufficiently studied. For instance, weak cytotoxicity of tentoxin against HepG2 [38] and HeLa cell lines [39] as well as some TCAs for various tumor cell lines [40,41] have been reported. A relationship between the production of TCAs and the cytotoxic activity of A. tenuissima MFP253011 extracts against Sf9 cells is more likely (Figure 7). The phytotoxicity of tentoxin [42] and TCA $1 \mathrm{a} / \mathrm{b}$ [43] to wheat, the host plant of S. graminum, may be responsible for the indirect effect of these substances on the aphid. In general, the spectrum of biological activity of tentoxin, dihydrotentoxin, and TCAs is still poorly understood [44], and an evaluation of their anti-insectan properties may be interesting. However, the yield of extracts containing these metabolites was relatively low (up to $200 \mathrm{mg} / \mathrm{L}$ ) (Figure 1). In this regard, this work may be planned for the future with optimized media conditions for their production.

PCA indicated that tenuazonic acid (TeA) was responsible for the larvicidal toxicity of some EtOAc extracts against G. mellonella (Figure 7), a model insect for studying the effects of toxins, immunosuppressants, and antibiotics as well as the relationship between pathogens and insects [45]. According to the literature, TeA was entomotoxic to the first instar larvae of the green bottle fly Lucilia sericata $\left(L_{50} 120 \mu \mathrm{g} / \mathrm{mL}\right.$ ) but was not active against other tested arthropods from various orders, namely Drosophila melanogaster (Diptera), Sitophilus granarius (Coleoptera), Aphis fabae (Hemiptera), and Tetranychus urticae (Trombidiformes) [11]. There are no data on the sensitivity of G. mellonella to this toxin. In order to study the entomotoxic properties of TeA, it was isolated from the culture of A. tenuissima MFP253011.

In liquid cultures of various strains of small-spored Alternaria spp., TeA content was detected with a yield of approximately $20-40 \mathrm{mg} / \mathrm{L}$. Commonly, the producer strains were grown on both mineral (Richard's and Czapek) and semi-synthetic (potato-dextrose broth, YES, and Richard's $+0.5 \%$ peptone) liquid media. The last medium allowed maximum toxin yields of up to 100-300 mg/L. When the fungi were grown on solid substrates, the yield of TeA reaches $\sim 200 \mathrm{mg} / \mathrm{kg}$ [46-50]. TeA was found to be a major toxin (up to $79 \%$ of the total content) in extracts of some $A$. tenuissima strains [51]. In our study, a relatively high yield of TeA was obtained (105 mg/L, 17\% of the extract) by submerged fermentation of A. tenuissima MFP253011 in a bioreactor on YMG medium, which stimulated the fungus to produce the relatively high yield of extractive matter (Figure 1), and by using the standard procedures for toxin isolation from the culture liquid. This may indicate that TeA is an easily available metabolite of $A$. tenuissima, which can be used for various biological assays requiring large amounts of the substances like entomotoxicity tests.

\subsection{Entomotoxicity of Tenuazonic Acid}

The injection method using G. mellonella larvae was successfully tested for the toxicological characterization of various chemicals [24]. For example, okadaic acid from shellfish at concentrations of $\geq 75 \mathrm{ng} /$ larva led to a significant decrease in the survival rate of G. mellonella (>65\% morality) $24 \mathrm{~h}$ after injection with an $\mathrm{LD}_{50}$ of $\sim 239 \mu \mathrm{g} / \mathrm{kg}$, comparable to its toxic dosage for rats [52]. This method has been used to assess the acute toxicity of metabolites of entomopathogenic fungi. In particular, a purified mixture of efrapeptins from Tolypocladium spp. was toxic to G. mellonella with an $\mathrm{LD}_{50}$ of $30 \mathrm{ng} / \mathrm{larva}$ [53]. At a dosage of $8.6 \mu \mathrm{g} /$ larva, beauvericin caused $37 \%$ mortality of $G$. mellonella after 12 days of incubation, with a median lethal time of approximately 6 days [54]. The $\mathrm{LD}_{50}$ of cordycepin was approximately $200 \mu \mathrm{g}$ /larva 6 days post-injection [55]. In our experiments, a significant decrease in $G$. mellonella viability was observed at a concentration of $20 \mu \mathrm{g} / \mathrm{larva}$ (ca. $100 \mathrm{mg} / \mathrm{kg}$ ) with an $\mathrm{LT}_{50}$ of $\sim 7$ days (Figure $8 \mathrm{~A}$ ). It was also shown for the first time that Zophobas morio larvae, a food insect used, for example, for feeding chickens [56], were also sensitive to injection with TeA at a dosage of $20 \mu \mathrm{g} / \mathrm{larva}(\sim 140 \mathrm{mg} / \mathrm{kg})$ with an $\mathrm{LT}_{50}$ 
of $\sim 4$ days (Figure $8 \mathrm{~B}$ ). These data demonstrate moderate levels of acute larvicidal activity of TeA comparable with entomotoxicity of beauvericin and cordycepin.

In oral assays, the addition of inactivated Fusarium spp. cultures to the feed of G. mellonella allowed the identification of the toxin-producing strains [57]. Diacetoxyscirpenol and neosolaniol isolated from F. sambucinum reduced the consumption of the spiked feed by G. mellonella ca. 50\% compared with the untreated control on caterpillars at a concentration of $50 \mu \mathrm{g} / \mathrm{g}$ of feed [58]. Oosporein from Beauveria brogniartii was nontoxic for the insect at a concentration of $142 \mu \mathrm{g} / \mathrm{g}$ of feed [59]. The bioactive alkaloids harman and nonharman, found in the entomopathogenic fungus Conidiobolus coronatus, when given in a non-lethal concentration of $1.25 \mathrm{mg} / \mathrm{g}$ of feed caused a significant delay in the development of G. mellonella [60]. In our experiments, no dead G. mellonella larvae were observed at TeA concentrations of $2.5 \mathrm{mg} / \mathrm{g}$ of feed within 10 days of incubation. Moreover, TeA was not $100 \%$ lethal even at $25 \mathrm{mg} / \mathrm{g}$ (data not shown). However, at a concentration of $250 \mu \mathrm{g} / \mathrm{g}$ of feed, the growth of larval biomass was significantly inhibited (Figure 9). Low toxicity coupled with biomass loss may indicate a rather antifeedant effect of TeA for G. mellonella; however, this hypothesis needs further evidence. Nothing was previously known about the effect of mycotoxins on another food insect, Acheta domesticus [61]. When TeA was added to the cricket diet, significant insect mortality was observed at a concentration of $250 \mu \mathrm{g} / \mathrm{g}$ of feed with $\mathrm{LT}_{50}$ for approximately 7 days (Figure 10).

In the contact intestinal assays, TeA was found to have moderate aphicidal activity, with $40 \%$ mortality $24 \mathrm{~h}$ after treatment at a concentration of $2 \mathrm{mg} / \mathrm{mL}$ (Figure 11A), whereas beauvericin was considerably more toxic, causing $100 \%$ mortality at a lower concentration of $0.5 \mathrm{mg} / \mathrm{mL}$. However, according to Ganassi et al. (2002) [62], beauvericin at the same concentration was less toxic to S. graminum (23\% mortality). The differences in the aphicidal activity of beauvericin may be explained by the variability of S. graminum populations. As mentioned above, some other fungal toxins of the genus, for example, diversolonic esters and chloromonilinic acid B, are more toxic than TeA, causing $70-80 \%$ mortality of $S$. graminum at a concentration of $1 \mathrm{mg} / \mathrm{mL}[9,63]$. The insecticide thiacloprid from the group of neonicotinoids was significantly more toxic to grass aphids, with an $\mathrm{LD}_{50}$ of approximately $210 \mu \mathrm{g} / \mathrm{mL}$ [64]. The sensitivity of aphids to seven organophosphorus insecticides varied within the $\mathrm{LD}_{50}$ range from 0.1 to $60 \mu \mathrm{g} / \mathrm{mL}$, depending on the level of resistance of S. graminum populations [65].

T. urticae was less sensitive to TeA than S. graminum. However, significant mortality of slightly more than $10 \%$ was detected at $0.5 \mathrm{mg} / \mathrm{mL}$ after $24 \mathrm{~h}$ of exposure (Figure 11). Beauvericin showed noticeable acaricidal properties, with $\mathrm{LD}_{50}$ values from 0.66 to $33 \mu \mathrm{g} / \mathrm{mL}$, depending on the sensitivity of the T. urticae population to the toxin [66]. The extract of the soil micromycete Aspergillus melleus, in which mellamide, ochratoxin C, nodulisporic acid, 7-oxocurvularin, and 6-(4'-hydroxy-2'-methyl phenoxy)-(-)-(3R)-mellein were detected, was significantly less toxic to the mites, with an $\mathrm{LD}_{50}$ of $10 \mathrm{mg} / \mathrm{mL}$ [67]. Thus, TeA demonstrated low activity against sucking insects in the contact intestinal assays. On other hand, evaluation of antifeedant and ovicidal effects of TeA on S. graminum and T. urticae appears interesting for further study.

Testing entomotoxic substances on insect and mammalian cells is helpful for the primary determination of the mechanisms of their action on arthropods [68]. Among 65 mycotoxins tested, TeA had relatively weak cytotoxicity to both insect and mammalian cells. It was shown that Sf9 cells are two times more sensitive to beauvericin than to TeA [69]. When tested on the porcine intestinal columnar epithelial cells (IPEC-J2 line), the cytotoxicity of TeA was 10 times lower than that of beauvericin [70]. However, in contrast to the latter, TeA caused rapid destruction of Sf9 cells at the minimum studied concentration of $15 \mu \mathrm{g} / \mathrm{mL}$ (Figure 12) and, therefore, may be of interest for mode of action studies.

\subsection{Practical Implications}

TeA, a derivative of tetramic acid, has gained great interest as a model molecule (toxin, pro-drug, and pro-pesticide) since (1) it is produced by a number of phytopathogenic fungi 
(Alternaria spp., Magnaporthe oryzae, and Phoma sorghina) [71]; (2) this toxin is one of the most common pollutants of food products, while its toxicity to invertebrates and vertebrates has been poorly understood [72,73]; (3) there are acaricides and insecticides (acetyl-CoA carboxylase inhibitors) from the tetramic acid group (for example, and spiropidion) that are effective against sucking arthropods [74]; (4) TeA, along with some other tetramic acid derivatives, is a promising natural herbicide [75], whereas its toxicity to beneficial insects (for example, pollinators, entomophages, and feed protein producers) has not been studied; and (5) methods of chemical synthesis of TeA and its derivatives with various useful properties have been developed $[11,71,76,77]$. However, the useful properties of direct use of $\mathrm{TeA}$ as a pesticide is still under question because of the restricted knowledge on its toxicity.

This study demonstrated moderate to low sensitivity of arthropods to TeA in various bioassays. Its entomotoxic activity against G. mellonella, Z. morio, and Acheta domesticus was shown for the first time. In natural materials, the TeA concentration does not commonly exceed the level of $100 \mathrm{ng} / \mathrm{g}$ and is clearly not entomotoxic. However, the maximum TeA content in food may vary greatly, reaching relatively high concentrations of up to $0.7 \mu \mathrm{g} / \mathrm{g}$ in grain products, up to $8 \mu \mathrm{g} / \mathrm{g}$ in vegetables, and up to $20 \mu \mathrm{g} / \mathrm{g}$ in spices [78,79]. Most likely, in cases of strongly moldy substrates or provisionally using TeA as an herbicide, the maximum concentrations can be sharply exceeded to affect sensitive arthropods. It makes sense to further study the spectrum of TeA entomotoxicity on harmful and useful insects (pollinators, entomophages, protein producers, etc.) and its action mechanisms on arthropods.

TeA has several molecular targets in the cells of various organisms. In plant cells, it inhibits the proton pump of the plasma membrane and photosynthesis [80,81], being one of the pathogenicity factors of phytopathogenic fungi that produce it [82]. Cell-free assays demonstrated $\mathrm{TeA}$ to be an antioxidant and a promising inhibitor of acetylcholinesterase and $\beta$-amyloid aggregation $[83,84]$. TeA is toxic to rodents and chickens, causing diarrhea, bleeding, and precancerous conditions. The toxin was presumed to negatively affect the digestive system of sensitive animals, but the exact mechanism of action of TeA is still unknown $[73,85]$.

The absence of considerable behavior and developmental changes of the treated insects, lack of tremor, weak sensitivity of sucking phytophages, and clear antifeedant effect may indicate that $\mathrm{TeA}$ is not an inhibitor of lipid biosynthesis as spirotetramat is; instead, it is an intestinal toxin for sensitive insects such as G. mellonella [86]. The mode of action of this toxin can be evaluated further using insect model systems, for example, on G. mellonella larvae and Sf9 cells. This may partially solve the enigma of the mammal toxicity of $\mathrm{TeA}$ as well as promote this compound as a pro-pesticide [87].

\section{Conclusions}

The extracts of $A$. tenuissima MFP253011 obtained by various methods showed a wide range of biological activity, including entomotoxic properties. Analysis of their composition and bioactivity allowed us to reveal several known mycotoxins and unidentified compounds that may be involved in the entomotoxic activity of the extracts. PCA of the data on the biological activity and the chemical composition of the extracts predicted that TeA has larvicidal activity against G. mellonella. Indeed, for the first time, TeA was found to display moderate entomotoxic properties, which were manifested in injection and oral tests to this insect and several others (Z. morio and A.domesticus).

The action mechanisms of TeA can be evaluated further using insect model systems, for example, on G. mellonella larvae and Sf9 cells. Another interesting issue for future studies is to determine the indirect effects of TeA on arthropods: are the entomotoxic effects correlated with phytotoxicity, are the intestinal microbiota of arthropods suppressed, and does this toxin affect their humoral immunity and sensitivity to entomopathogens? 
Author Contributions: Conceptualization, A.B.; methodology, A.B., E.S., I.S., and O.T.; formal analysis, D.S. and A.B.; investigation, D.S, A.D., V.D., E.S., and I.S.; writing-original draft preparation, D.S. and A.B.; writing-review and editing, Q.H. and A.B.; supervision, A.B.; project administration, A.B.; funding acquisition, A.B. All authors have read and agreed to the published version of the manuscript.

Funding: The reported study was funded by the Russian Foundation for Basic Research (RFBR project N 19-34-90181) and partly by RFBR-NSFC (project N 20-516-53009) and the National Natural Science Foundation of China (project N 32011530071).

Institutional Review Board Statement: Not applicable.

Informed Consent Statement: Not applicable.

Data Availability Statement: All relevant data are included within the manuscript.

Acknowledgments: Vadim Kryukov (Institute of Systematics and Ecology of Animals Novosibirsk, Russia) for helpful statistical advice; Dmitry Kochura and Leonid Chisty (Research Institute of Hygiene, Occupational Pathology, and Human Ecology, Federal Medical Biological Agency, Saint Petersburg, Russia) for LC-MS and NMR experiments.

Conflicts of Interest: The authors declare no conflict of interest.

\section{References}

1. Berestetskiy, A.; Hu, Q. The chemical ecology approach to reveal fungal metabolites for arthropod pest management. Microorganisms 2021, 9, 1379. [CrossRef] [PubMed]

2. Berestetskiy, A.O.; Gannibal, F.B.; Minkovich, E.V.; Osterman, I.A.; Salimova, D.R.; Sergiev, P.V.; Sokornova, S.V. Spectrum of biological activity of the Alternaria fungi isolated from the phyllosphere of herbaceous plants. Microbiology 2018, 87, 806-816. [CrossRef]

3. Berestetskiy, A.O.; Apollonova, L.S.; Sokornova, S.V.; Chermenskaya. T., D. Insecticidal properties of phytopathogenic ascomycetes. Vestn. Zashchity Rasteniy 2015, 85, 52-54. (In Russian)

4. Singh, B.; Thakur, A.; Kaur, S.; Chadha, B.S.; Kaur, A. Acetylcholinesterase inhibitory potential and insecticidal activity of an endophytic Alternaria sp. from Ricinus communis. Appl. Biochem. Biotechnol. 2012, 168, 991-1002. [CrossRef] [PubMed]

5. Kaur, H.P.; Singh, B.; Thakur, A.; Kaur, A.; Kau, S. Studies on immunomodulatory effect of endophytic fungus Alternaria alternate on Spodoptera litura. J. Asia-Pac. Entomol. 2015, 18, 67-75. [CrossRef]

6. Kaur, J.; Sharma, A.; Sharma, M.; Manhas, R.K.; Kaur, S.; Kaur, A. Effect of $\alpha$-glycosidase inhibitors from endophytic fungus Alternaria destruens on survival and development of insect pest Spodoptera litura Fab. and fungal phytopathogens. Sci. Rep. 2019, 9, 1-13. [CrossRef] [PubMed]

7. Buchwaldt, L.; Green, H. Phytotoxicity of destruxin B and its possible role in the pathogenesis of Alternaria brassicae. Plant Pathol. J. 1992, 41, 55-63. [CrossRef]

8. Sowjanya Sree, K.; Padmaja, V.; Murthy, Y.L. Insecticidal activity of destruxin, a mycotoxin from Metarhizium anisopliae (Hypocreales), against Spodoptera litura (Lepidoptera: Noctuidae) larval stages. Pest Manag. Sci. 2008, 64, 119-125. [CrossRef]

9. Dalinova, A.; Chisty, L.; Kochura, D.; Garnyuk, V.; Petrova, M.; Prokofieva, D.; Yurchenko, A.; Dubovik, V.; Ivanov, A.; Smirnov, S.; et al. Isolation and bioactivity of secondary metabolites from solid culture of the fungus, Alternaria sonchi. Biomolecules 2020, 10, 81. [CrossRef]

10. Bhagat, J.; Kaur, A.; Kaur, R.; Yadav, A.K.; Sharma, V.; Chadha, B.S. Cholinesterase inhibitor (Altenuene) from an endophytic fungus Alternaria alternata: Optimization, purification and characterization. J. Appl. Microbiol. 2016, 121, 1015-1025. [CrossRef]

11. La Croix, E.A.S.; Mhasalkar, S.E.; Mamalis, P.; Harrington, F.P. Insecticidal activity of some tenuazonic acid analogues. Pestic. Sci. 1975, 6, 491-496. [CrossRef]

12. Reid, W.R.; Parker, B.L.; Gouli, S.Y.; Skinner, M.; Gouli, V.V.; Teillon, H.B. Fungi associated with the hemlock woolly adelgid, Adelges tsugae, and assessment of entomopathogenic isolates for management. J. Insect Sci. 2010, 10, 1-18. [CrossRef] [PubMed]

13. Sharma, I.; Sharma, A. Use of Alternaria spp. as a pest control agent: A review. World App. Sci. J. 2014, 31, 1869-1872. [CrossRef]

14. Wakil, W.; Usman Ghazanfar, M.; Yasin, M. Naturally occurring entomopathogenic fungi infecting stored grain insect species in Punjab, Pakistan. J. Insect Sci. 2014, 14, 182. [CrossRef] [PubMed]

15. Shabana, Y.M.; Ragab, M.E. Alternaria infectoria, a promising biological control agent for the fig wax scale, Ceroplastes rusci (Homoptera: Coccidae), in Egypt. Biocontrol Sci. Technol. 1997, 7, 553-564. [CrossRef]

16. Christias, C.H.; Hatzipapas, P.; Dara, A.; Kaliafas, A.; Chrysanthis, G. Alternaria alternata, a new pathotype pathogenic to aphids. BioControl 2001, 46, 105-124. [CrossRef]

17. Hatzipapas, P.; Kalosak, K.; Dara, A.; Christias, C. Spore germination and appressorium formation in the entomopathogenic Alternaria alternata. Mycol. Res. 2002, 106, 1349-1359. [CrossRef]

18. Gannibal, P.B. Species of the genus Alternaria revealed in Russia and some neighboring territories. Mikol. Fitopatol. 2015, 49, 374-385. (In Russian) 
19. Yang, F.Z.; Yang, B.; Li, B.B.; Xiao, C. Alternaria toxin-induced resistance in rose plants against rose aphid (Macrosiphum rosivorum): Effect of tenuazonic acid. J. Zhejiang Univ. Sci. B 2015, 16, 264-274. [CrossRef]

20. Basit, A.; Farhan, M.; Abbas, M.; Wang, Y.; Zhao, D.G.; Mridha, A.U.; Al-tawaha, A.R.M.S.; Bashir, M.A.; Arif, M.; Ahmed, S.; et al. Do microbial protein elicitors PeaT1 obtained from Alternaria tenuissima and PeBL1 from Brevibacillus laterosporus enhance defense response against tomato aphid (Myzus persicae)? Saudi J. Biol. Sci. 2021, 28, 3242-3248. [CrossRef]

21. Salimova, D.R.; Kochura, D.S.; Sokornova, S.V.; Orina, A.S.; Hannibal, F.B.; Berestetskiy, A.O. Identification and toxigenic properties of Alternaria japonica strains. Mikol. Fitopatol. 2021, 55, 203-218. (In Russian) [CrossRef]

22. Mikula, H.; Horkel, E.; Hans, P.; Hametner, C.; Fröhlich, J. Structure and tautomerism of tenuazonic acid-A synergetic computational and spectroscopic approach. J. Hazard. Mater. 2013, 250, 308-317. [CrossRef] [PubMed]

23. Chermenskaya, T.D.; Stepanycheva, E.A.; Shchenikova, A.V.; Savelieva, E.I.; Chakaeva, A.S. Insecticidal effects of Ungernia severtzovii bulb extracts against the grain aphid Schizaphis graminum (Rondani). Ind. Crops Prod. 2012, 36, 122-126. [CrossRef]

24. Allegra, E.; Titball, R.W.; Carter, J.; Champion, O.L. Galleria mellonella larvae allow the discrimination of toxic and non-toxic chemicals. Chemosphere 2018, 198, 469-472. [CrossRef] [PubMed]

25. Berestetskii, A.O.; Yuzikhin, O.S.; Katkova, A.S.; Dobrodumov, A.V.; Sivogrivov, D.E.; Kolombet, L.V. Isolation, identification, and characteristics of the phytotoxin produced by the fungus Alternaria cirsinoxia. Appl. Biochem. Microbiol. 2010, 46, 75-79. [CrossRef]

26. Balouiri, M.; Sadiki, M.; Ibnsouda, S.K. Methods for in vitro evaluating antimicrobial activity: A review. J. Pharm. Anal. 2016, 6, 71-79. [CrossRef] [PubMed]

27. Rincón, R.A.; Rodríguez, D.; Coy-Barrera, E. Botanicals against Tetranychus urticae Koch under laboratory conditions: A survey of alternatives for controlling pest mites. Plants 2019, 8, 272. [CrossRef]

28. Kono, Y.; Gardner, J.M.; Takeuchi, S. Structure of the host-selective toxins produced by a pathotype of Alternaria citri causing brown spot disease of mandarins. Agr. Biol. Chem. 1986, 50, 801-804. [CrossRef]

29. Liebermann, B.; Ellinger, R.; Günther, W.; Ihn, W.; Gallander, H. Tricycloalternarenes produced by Alternaria alternata related to ACTG-toxins. Phytochemistry 1997, 46, 297-303. [CrossRef]

30. Ostry, V. Alternaria mycotoxins: An overview of chemical characterization, producers, toxicity, analysis and occurrence in foodstuffs. World Mycotoxin J. 2008, 1, 175-188. [CrossRef]

31. Gotthardt, M.; Kanawati, B.; Schmidt, F.; Asam, S.; Hammerl, R.; Frank, O.; Hofmann, T.; Schmitt-Kopplin, P.; Rychlik, M. Comprehensive analysis of the Alternaria mycobolome using mass spectrometry based metabolomics. Mol. Nutr. Food Res. 2019, 64, 1900558. [CrossRef]

32. Wang, J.T.; Ma, Z.H.; Wang, G.K.; Xu, F.Q.; Chen, L.; Yang, Y.; Wang, G.; Liu, J.S. Four meroterpenoids from Alternaria alternata isolated from Paeonia lactiflora. Phytochem. Lett. 2019, 31, 1-4. [CrossRef]

33. Lou, J.; Fu, L.; Peng, Y.; Zhou, L. Metabolites from Alternaria fungi and their bioactivities. Molecules 2013, 18, 5891-5935. [CrossRef]

34. Pinto, V.E.; Patriarca, A. Alternaria species and their associated mycotoxins. In Methods in Molecular Biology, 2nd ed.; Moretti, A., Susca, A., Eds.; Humana Press: New York, NY, USA, 2017; Chapter 1542; pp. 13-32. [CrossRef]

35. Dalinova, A.A.; Salimova, D.R.; Berestetskiy, A.O. Fungi of the genera Alternaria as producers of biological active compounds and mycoherbicides. Appl. Biochem. Microbiol. 2020, 56, 256-272. [CrossRef]

36. DesRochers, N.; Walsh, J.P.; Renaud, J.B.; Seifert, K.A.; Yeung, K.K.-C.; Sumarah, M.W. Metabolomic profiling of fungal pathogens responsible for root rot in American ginseng. Metabolites 2020, 10, 35. [CrossRef] [PubMed]

37. Lotfy, M.M.; Sayed, A.M.; AboulMagd, A.M.; Hassan, H.M.; El Amir, D.; Abouzid, S.F.; El-Gendy, A.O.; Rateb, M.E.; Abdelmohsen, U.R.; Alhadrami, H.; et al. Metabolomic profiling, biological evaluation of Aspergillus awamori, the river Nile-derived fungus using epigenetic and OSMAC approaches. RSC Adv. 2021, 11, 6709-6719. [CrossRef]

38. Hessel-Pras, S.; Kieshauer, J.; Roenn, G.; Luckert, C.; Braeuning, A.; Lampen, A. In vitro characterization of hepatic toxicity of Alternaria toxins. Mycotoxin Res. 2019, 35, 157-168. [CrossRef] [PubMed]

39. Abdou, R.; Dawoud, M. Cytotoxic metabolites of Alternaria alternata, an endophyte of the medicinal plant Bidens bipinnata. Int. J. Pharm. Pharm. Sci. 2020, 12, 42-48. [CrossRef]

40. Shen, L.; Tian, S.J.; Song, H.L.; Chen, X.; Guo, H.; Wan, D.; Wang, Y.R.; Wang, F.W.; Liu, L.J. Cytotoxic tricycloalternarene compounds from endophyte Alternaria sp. W-1 associated with Laminaria japonica. Mar. Drugs 2018, 16, 402. [CrossRef] [PubMed]

41. Zhang, G.; Wang, L.; Jiao, J.; Liu, D.; Zhang, X.; Li, J.; Che, Q.; Zhu, T.; Li, D. Cytotoxic meroterpenoids from the sponge-associated fungus Alternaria sp. JJY-32. Chem. Biodivers. 2020, 17, e2000226. [CrossRef]

42. Klotz, M.G.; Erdei, L. Effect of tentoxin on $\mathrm{K}^{+}$transport in winter wheatseedlings of different $\mathrm{K}^{+}$-status. Physiol. Plant. 1988, 72, 298-304. [CrossRef]

43. Sugawara, F.; Uzawa, J.; Esumi, Y.; Suzuki, M.; Yoshida, S.; Strobel, G.; Steiner, J.L.R.; Clardy, J. Phytotoxins from the Septoria spp. plant pathogenic fungus on leafy spurge. Biosci. Biotechnol. Biochem. 1998, 62, 638-642. [CrossRef]

44. Aichinger, G.; Del Favero, G.; Warth, B.; Marko, D. Alternaria toxins-Still emerging? Compr. Rev. Food Sci. Food Saf. 2021, 1-17. [CrossRef]

45. Cutuli, M.A.; Petronio, G.P.; Vergalito, F.; Magnifico, I.; Pietrangelo, L.; Venditti, N.; Di Marco, R. Galleria mellonella as a consolidated in vivo model hosts: New developments in antibacterial strategies and novel drug testing. Virulence 2019, 10, 527-541. [CrossRef]

46. Kinoshita, T.; Renbutsu, Y.; Khan, I.D.; Kohmojo, K.; Nishimura, S. Distribution of tenuazonic acid production in the genus Alternaria and its pathological evaluation. Jpn. J. Phytopathol. 1972, 38, 397-404. [CrossRef] 
47. Davis, N.D.; Diener, U.L.; Morgan-Jones, G. Tenuazonic acid production by Alternaria alternata and Alternaria tenuissima isolated from cotton. Appl. Environ. Microbiol. 1977, 34, 155-157. [CrossRef] [PubMed]

48. Brzonkalik, K.; Herrling, T.; Syldatk, C.; Neumann, A. Process development for the elucidation of mycotoxin formation in Alternaria alternata. AMB Express 2011, 1, 27. [CrossRef] [PubMed]

49. Brzonkalik, K.; Hümmer, D.; Syldatk, C.; Neumann, A. Influence of $\mathrm{pH}$ and carbon to nitrogen ratio on mycotoxin production by Alternaria alternata in submerged cultivation. AMB Express 2012, 2, 1-8. [CrossRef] [PubMed]

50. Meena, M.; Swapnil, P.; Upadhyay, R.S. Isolation, characterization and toxicological potential of Alternaria-mycotoxins (TeA, $\mathrm{AOH}$ and AME) in different Alternaria species from various regions of India. Sci. Rep. 2017, 7, 8777. [CrossRef] [PubMed]

51. Zwickel, T.; Kahl, S.M.; Klaffke, H.; Rychlik, M.; Müller, M.E.H. Spotlight on the underdogs-An analysis of underrepresented Alternaria mycotoxins formed depending on varying substrate, time and temperature conditions. Toxins 2016, 8, 344. [CrossRef]

52. Coates, C.J.; Lim, J.; Harman, K.; Rowley, A.F.; Griffiths, D.J.; Emery, H.; Layton, W. The insect, Galleria mellonella, is a compatible model for evaluating the toxicology of okadaic acid. Cell Biol. Toxicol. 2019, 35, 219-232. [CrossRef]

53. Bandani, A.R.; Khambay, B.P.S.; Faull, J.L.; Newton, R.; Deadman, M.; Butt, T.M. Production of efrapeptins by Tolypocladium species and evaluation of their insecticidal and antimicrobial properties. Mycol. Res. 2000, 104, 537-544. [CrossRef]

54. Safavi, S.A. In vitro and in vivo induction, and characterization of beauvericin isolated from Beauveria bassiana and its bioassay on Galleria mellonella larvae. J. Agric. Sci. Technol. 2013, 15, 1-10.

55. Woolley, V.C.; Teakle, G.R.; Prince, G.; de Moor, C.H.; Chandler, D. Cordycepin, a metabolite of Cordyceps militaris, reduces immune-related gene expression in insects. J. Invertebr. Pathol. 2020, 177, 107480. [CrossRef] [PubMed]

56. Benzertiha, A.; Kierończyk, B.; Kołodziejski, P.; Pruszyńska-Oszmałek, E.; Rawski, M.; Józefiak, D.; Józefiak, A. Tenebrio molitor and Zophobas morio full-fat meals as functional feed additives affect broiler chickens' growth performance and immune system traits. Poult. Sci. 2020, 99, 196-206. [CrossRef] [PubMed]

57. Mulè, G.; Logrieco, A.; Bottalico, A.; Stea, G. Screening for Fusarium toxigenic isolates using larvae of Galleria mellonella. Mycotoxin Res. 1994, 10, 41-46. [CrossRef]

58. Mulè, G.; D'Ambrosio, A.; Logrieco, A.; Bottalico, A. Toxicity of mycotoxins of Fusarium sambucinum for feeding in Galleria mellonella. Entomol. Exp. Appl. 1992, 62, 17-22. [CrossRef]

59. Abendstein, D.; Schweigkofler, W.; Strasser, H. Effect of the fungal metabolite oosporein on feeding behavior and survival of larvae of Melolontha melolontha L. and Galleria mellonella L. Laimburg J. 2001, 1, 1-4.

60. Wrońska, A.K.; Boguś, M.I.; Kaczmarek, A.; Kazek, M. Harman and norharman, metabolites of entomopathogenic fungus Conidiobolus coronatus (Entomopthorales), disorganize development of Galleria mellonella (Lepidoptera) and affect serotoninregulating enzymes. PLoS ONE 2018, 13, e0204828. [CrossRef] [PubMed]

61. Fernandez-Cassi, X.; Supeanu, A.; Jansson, A.; Boqvist, S.; Vagsholm, I. Novel foods: A risk profile for the house cricket (Acheta domesticus). EFSA J. 2018, 16, e16082. [CrossRef]

62. Ganassi, S.; Moretti, A.; Pagliai, M.B.; Logrieco, A.; Sabatini, M.A. Effects of beauvericin on Schizaphis graminum (Aphididae). J. Invertebr. Pathol. 2002, 80, 90-96. [CrossRef]

63. Berestetskiy, A.O.; Dalinova, A.A.; Dubovik, V.R.; Grigoryeva, E.N.; Kochura, D.M.; Senderskiy, I.V.; Smirnov, S.N.; Stepanycheva, E.A.; Turaeva, S.M. Analysis and isolation of secondary metabolites of Bipolaris sorokiniana by different chromatography techniques and the spectrum of their biological activity. Appl. Biochem. Microbiol. 2020, 56, 569-582. [CrossRef]

64. Aeinehchi, P.; Naseri, B.; Rafiee Dastjerdi, H.; Nouri-Ganbalani, G.; Golizadeh, A. Lethal and sublethal effects of thiacloprid on Schizaphis graminum (Rondani) (Hemiptera: Aphididae) and its predator Hippodamia variegata (Goeze) (Coleoptera: Coccinellidae). Toxin Rev. 2019, 1-11. [CrossRef]

65. Gao, J.R.; Zhu, K.Y. Comparative toxicity of selected organophosphate insecticides against resistant and susceptible clones of the greenbug, Schizaphis graminum (Homoptera: Aphididae). J. Agric. Food Chem. 2000, 48, 4717-4722. [CrossRef] [PubMed]

66. Al Khoury, C.; Guillot, J.; Nemer, N. Lethal activity of beauvericin, a Beauveria bassiana mycotoxin, against the two-spotted spider mites, Tetranychus urticae Koch. J. Appl. Entomol. 2019, 143, 974-983. [CrossRef]

67. Osman, M.E.; Elnasr, A.A.A.; Nawar, M.A.; Hefnawy, G.A. Myco-metabolites as biological control agents against the two-spotted spider mite, Tetranychus urticae Koch (Acari: Tetranychidae). Egypt J. Biol. Pest Control 2019, 29, 1-10. [CrossRef]

68. Mak, M.; Beattie, K.D.; Basta, A.; Randall, D.; Chen, Z.; Spooner-Hart, R. Triangulation of methods using insect cell lines to investigate insecticidal mode-of-action. Pest Manag. Sci. 2021, 77, 492-501. [CrossRef]

69. Boguś, M.I.; Wrońska, A.K.; Kaczmarek, A.; Boguś-Sobocińska, M. In vitro screening of 65 mycotoxins for insecticidal potential. PLoS ONE 2021, 16, e0248772. [CrossRef]

70. Novak, B.; Rainer, V.; Sulyok, M.; Haltrich, D.; Schatzmayr, G.; Mayer, E. Twenty-eight fungal secondary metabolites detected in pig feed samples: Their occurrence, relevance and cytotoxic effects in vitro. Toxins 2019, 11, 537. [CrossRef]

71. Chen, S.; Qiang, S. Recent advances in tenuazonic acid as a potential herbicide. Pestic. Biochem. Phys. 2017, $143,252-257$. [CrossRef]

72. Fraeyman, S.; Croubels, S.; Devreese, M.; Antonissen, G. Emerging Fusarium and Alternaria mycotoxins: Occurrence, toxicity and toxicokinetics. Toxins 2017, 9, 228. [CrossRef]

73. Gruber-Dorninger, C.; Novak, B.; Nagl, V.; Berthiller, F. Emerging mycotoxins: Beyond traditionally determined food contaminants. J. Agric. Food Chem. 2017, 65, 7052-7070. [CrossRef] [PubMed] 
74. Muehlebach, M.; Buchholz, A.; Zambach, W.; Schaetzer, J.; Daniels, M.; Hueter, O.; Kloer, D.P.; Lind, R.; Maienfisch, P.; Pierce, A.; et al. Spiro N-methoxy piperidine ring containing aryldiones for the control of sucking insects and mites: Discovery of spiropidion. Pest Manag. Sci. 2020, 76, 3440-3450. [CrossRef] [PubMed]

75. Zhou, B.; Wang, H.; Meng, B.; Wei, R.; Wang, L.; An, C.; Chen, S.; Yang, C.; Qiang, S. An evaluation of tenuazonic acid, a potential biobased herbicide in cotton. Pest Manag. Sci. 2019, 75, 2482-2489. [CrossRef]

76. Fischer, R.; Lehr, S.; Arnold, C.; Auler, T.; Dittgen, J.; Feucht, D.; Franken, E.M.; Hempel, W.; Hills, M.J.; Kehne, H.; et al. Trifluoromethoxyphenyl-Substituted Tetramic Acid Derivatives as Pesticides and/or Herbicides. WO Patent N 2008067873A1, 12 June 2008. Available online: https:/ / patents.google.com/patent/WO2008067873A1/da (accessed on 25 August 2021).

77. Chen, M.; Geng, C.W.; Han, L.; Liu, Y.; Yu, Y.K.; Lu, A.M.; Yang, C.L.; Li, G.H. Design, synthesis, crystal structure, and herbicidal activity of novel pyrrolidine-2,4-dione derivatives incorporating an alkyl ether pharmacophore with natural tetramic acids as lead compounds. New J. Chem. 2021, 45, 5621-5630. [CrossRef]

78. Sanzani, S.M.; Gallone, T.; Garganese, F.; Caruso, A.G.; Amenduni, M.; Ippolito, A. Contamination of fresh and dried tomato by Alternaria toxins in southern Italy. Food Addit. Contam. A 2019, 36, 789-799. [CrossRef] [PubMed]

79. Mujahid, C.; Savoy, M.C.; Baslé, Q.; Woo, P.M.; Ee, E.C.Y.; Mottier, P.; Bessaire, T. Levels of Alternaria toxins in selected food commodities including green coffee. Toxins 2020, 12, 595. [CrossRef] [PubMed]

80. Chen, S.; Yin, C.; Qiang, S.; Zhou, F.; Dai, X. Chloroplastic oxidative burst induced by tenuazonic acid, a natural photosynthesis inhibitor, triggers cell necrosis in Eupatorium adenophorum Spreng. Biochim. Biophys. Acta Bioenerg. 2010, 1797, $391-405$. [CrossRef] [PubMed]

81. Bjørk, P.K.; Rasmussen, S.A.; Gjetting, S.K.; Havshøi, N.W.; Petersen, T.I.; Ipsen, J.Ø.; Larsen, T.O.; Fuglsang, A.T. Tenuazonic acid from Stemphylium loti inhibits the plant plasma membrane $\mathrm{H}^{+}$-ATPase by a mechanism involving the C-terminal regulatory domain. New Phytol. 2020, 226, 770-784. [CrossRef]

82. Shi, J.; Zhang, M.; Gao, L.; Yang, Q.; Kalaji, H.M.; Qiang, S.; Strasser, R.J.; Chen, S. Tenuazonic acid-triggered cell death is the essential prerequisite for Alternaria alternata (Fr.) Keissler to infect successfully host Ageratina adenophora. Cells 2021, 10, 1010. [CrossRef]

83. Piemontese, L.; Vitucci, G.; Catto, M.; Laghezza, A.; Perna, F.M.; Rullo, M.; Loiodice, F.; Capriati, V.; Solfrizzo, M. Natural scaffolds with multi-target activity for the potential treatment of Alzheimer's disease. Molecules 2018, 23, 2182. [CrossRef] [PubMed]

84. Poliseno, V.; Chaves, S.; Brunetti, L.; Loiodice, F.; Carrieri, A.; Laghezza, A.; Tortorella, P.; Magalhães, J.D.; Cardoso, S.M.; Santos, M.A.; et al. Derivatives of tenuazonic acid as potential new multi-target anti-Alzheimer's disease agents. Biomolecules 2021, 11, 111. [CrossRef] [PubMed]

85. Kumari, A.; Tirkey, N.N. Tenuazonic Acid: A potent mycotoxin. In Recent Trends in Human and Animal Mycology, 2nd ed.; Singh, K., Srivastava, N., Eds.; Springer Nature: Singapore, 2019; Chapter 8; pp. 203-211. [CrossRef]

86. Jeschke, P. Status and outlook for acaricide and insecticide discovery. Pest Manag. Sci. 2021, 77, 64-76. [CrossRef] [PubMed]

87. Senthil-Nathan, S. A review of biopesticides and their mode of action against insect pests. In Environmental Sustainability; Thangavel, P., Sridevi, G., Eds.; Springer: New Delhi, India, 2015; pp. 49-63. [CrossRef] 